Article

\title{
The Influence of the Built Environment of Neighborhoods on Residents' Low-Carbon Travel Mode
}

\author{
Caiyun Qian, Yang Zhou *, Ze Ji and Qing Feng
}

School of Architecture, Nanjing Tech University, Nanjing 211800, China; QCY13770584818@njtech.edu.cn (C.Q.); kizer@njtech.edu.cn (Z.J.); 873793053@njtech.edu.cn (Q.F.)

* Correspondence: zhouyang0206@njtech.edu.cn; Tel.: +86-025-5813-9459

Received: 29 January 2018; Accepted: 13 March 2018; Published: 15 March 2018

\begin{abstract}
Motor vehicle travel is one of the causes of aggravation of $\mathrm{CO}_{2}$ emission, environmental issues and urban problems. The advocation of low-carbon travel is necessary for the achievement of low-carbon city construction and sustainable development in the future. Many studies have shown that built environment tends to influence residents' travel behavior, and most studies are demonstrated from the macro level of metropolis. However, from the perspective of neighborhoods, much less attention has been paid, especially in developing countries including China. This study chooses 15 neighborhoods in the main districts of Nanjing in China, taking the location of neighborhoods and residents' socio-economic attributes into consideration, to examine the effects of residential built environment on residents' mode choice of different travel types, and to propose the recommended values for the most significant variables. The residential built environment attributes are from three dimensions of land use, road network system and transit facilities. The method of this study is three-step and successive. Primarily, a correlation analysis model is applied to initially examine the role that residents' socio-economic attributes and residential built environment attributes play on residents' low-carbon travel of three different travel types respectively. Primary significant attributes from these two aspects are preliminarily screened out for the re-screening in the next step. In addition, the study uses multivariate logit regression modeling approach, with significant socio-economic attributes as concomitant variables, to further re-screen out the key variables of built environment. Furthermore, a unary linear regression model is applied to propose the recommended values for the key built environment variables.
\end{abstract}

Keywords: neighborhood; built environment; low carbon travel; correlation analysis model; multivariate logit regression model; unary linear regression model

\section{Introduction}

The greenhouse effect has brought rigorous challenge for society and ecology in a global context. As Intergovernmental Panel on Climate Change (IPCC) reported in 2014 that transport accounted for $14 \%$ of total greenhouse gas emission worldwide [1]. China is one of the largest $\mathrm{CO}_{2}$ emitters in the world: from 1985 to 2015, the number of private cars increased at an average annual rate of 22.9\% [2]. The increase in the population of private cars as well as the daily usage has posed severe challenges to urban road network capacity, parking space, travel time, energy consumption, air pollution and comfort of urban spaces. Residents' travel mode choice has an important impact on urban transport and carbon emissions. The "low-carbon travel", which is dominated by public transport, non-motor vehicles and walking, is based on low energy consumption and low pollution, aiming to reduce the carbon dioxide emissions during the trip. It is of great importance to alleviating urban traffic congestion and achieving urban sustainable development. Neighborhoods, as an important functional 
part of the city, are the spatial carriers of daily life of residents, and their built environment is associated with the choice of residents' travel mode [3,4] .

Studies on the factors that affect the travel mode of residents carried out by researchers can be divided into two categories: the socio-economic attributes of residents and the built environment attributes.

Based on the US Department of Transportation's 2001 National Household Travel Survey, Agrawal and Schimek [5] analyzed the walking trip data of residents, evaluated the condition of walking trip in the US and examined the influential factors on walking. Further, the results indicated that highly educated people are more willing to choose to walk whether for utility trips or recreational trips. The high-income earners are more likely to choose the non-walking mode for commuting trips but the walking mode for the recreational travel. Based on panel data from 1978 to 2008 in some countries in Europe and Japan, Okada [6] examined the results from 25 OECD countries, consisting mainly of European countries and Japan, indicate that there is a quadratic relationship between $\mathrm{CO}_{2}$ emissions per capita and the share of aged population, and that the turning point is around 16 percent. Wei and Pan [7] analyzed and studied the sub-districts in Hangzhou. It is concluded that commuting trips are significantly related to household incomes. Different economic status leads to different influence of the land use variables on the mode choice of commuting travel. Based on the data obtained from the low-carbon city questionnaire survey carried out in Wuhan in 2010, Huang, Du, Liu et al. [8,9] conducted the multiple linear regression analysis and the results indicated that the carbon emissions of household daily traffic trips are significantly correlated to the monthly household income, the education level of female family members, the number of permanent residents of the family. Based on the National Household Transportation Survey (NHTS) in the US in 2009, Merlin [10] believed that the influence of the built environment on household participation in non-work activities is greater than expected. In addition, activity participation in households with limited vehicle access is for the most part not affected by the built environment. Taking physical environment attributes such as population density, mixed degree of land use and so on into consideration, most of the relative studies presented the socio-economic attributes that play an important role on facilitating walking and other low-carbon mode. These socio-economic attributes mainly include age, educational attainment, family income and population. Because of the differences of geographical areas and research scales, the influence of each factor may not be consistent. Therefore, it is necessary to study residents' socio-economic attributes in the research area, and specifically focuses on their influence on residents' travel mode.

Cervero and Kockelman [11] condensed the built environment characteristics into density, diversity of land use, and urban design, namely, the "3Ds" which has been widely acknowledged. Then Cervero and Jin [12] added two elements: the distance to transit and the destination accessibility, which further emphasized the impact of the interaction between public transport and land use on residents' travel, and extended the "3Ds" to "5Ds". In addition, many researchers believed that the optimization of the built environment is an important and long-term strategy to reduce residents' dependence on cars $[13,14]$.

Based on the empirical study of five sample neighborhoods in San Francisco, Kitamura, Mokhtarian and Laidet [15] concluded that the variables such as residential density, public transit accessibility, mixed use of land and the presence of sidewalks were significantly related to residents' travel behavior in built environments. Moreover, it suggests that land use policies promoting higher densities and mixtures may not alter travel demand materially unless residents' attitudes are also changed. Reilly and Landis [16] conducted a survey of residents' travel data in the San Francisco Bay Area and found that built environment has an impact on residents' travel mode. As for entertainment travel, a $25 \%$ increase in the density of road intersections increased the probability of choosing public transportation by $62 \%$ and the probability of choosing walking by $45 \%$. Dygryn, Mitas and Stelzer [17] defined the walkability index to measure walking friendliness. Among them, the built environment characteristics such as residential density, road connectivity and mixed use of land have a positive correlation with walkability index. Ewing and Cervero [18] analyzed a large number of empirical studies based on meta-analysis 
and concluded that the distance to bus stops, road network shape variables and land-use mixed degree are important variables that influence residents' mode choice of public transport. Hong, Shen and Zhang [19] based on the survey data of household activities of the Puget Sound Regional Council in 2006, established the multilevel linear model to integrate the spatial relations of various TAZs into the study area, and drew the conclusion that residents in the area with higher density and mixed land use are less likely to choose motor vehicle travel. Ding, Wang and Xie et al. [20] took the empirical study in Washington DC as the study area. It is considered that the built environment around the home location and work place has a significant impact on the travel distance of commuting, and the building coverage around the work place has a greater impact on residents' travel.

Compared with other countries, China has lagged behind in studying the relationship between the built environment and residents' travel modes. At present, the qualitative studies gradually move towards quantitative studies. Pan, Shen and Zhang [21] selected four blocks in different locations in Shanghai as research subjects. The analysis showed that in Luwan block which has relatively high road network density, residents have relatively short travel distances and are more willing to choose low-carbon travel mode. Taking Nanjing as an example, Shi and Ju [22] studied the impact of land use, road design, bus supply and socio-economic attributes of residents on bus travel. The specific built environment variables and the characteristics of residents' socio-economic attributes are regarded as independent variables and the bus sharing rate as a dependent variable. On this basis, the multiple linear regression model was established and the results indicated that there is a respectively significantly positive correlation, positive correlation, positive correlation and negative correlation between the bus sharing rate and four variables respectively, including the mixed degree of land use, the density of cross intersection, transportation line overlap factor and the distance to the nearest subway station. Based on 21 blocks in Shanghai, Chen, Wang and Xi et al. [23] studied the influence of the spatial pattern on pedestrian behavior in Shanghai. According to the attributes of population density, storefront density, bus route density and the density of entrances and exits in neighborhoods, they proposed appropriate value of each attribute. Studies listed above are all about the essential influence of built environment attributes on travel, such as urban location, land use and road network et al. In addition, analyses suggest that depending on geographic scales and tour types, some of these effects may translate into different empirical results.

However, some issues still need further research in the previous studies. Firstly, most of the existing studies are concentrated on the macro level of metropolis, while there are relatively few studies on the level of neighborhoods. Taking neighborhood as a unit to survey on residents' socio-economic attributes, the survey content is more detailed, more comprehensive and press closer to residents' travel mode in daily life. As the origin place of residents' most travel trips, the built environment of neighborhoods needs more specific research. Secondly, relative studies mostly concentrate on travel overall or commuter travel, while studies that classify travel types by travel purposes are limited. Thirdly, due to the different economy developing levels, different urban construction conditions and different national conditions, some conclusions may not be universal. In addition, due to the similarities and differences of local characteristics, sample selection and establishment of analytical models, the related quantitative research results may not be consistent.

Compared with the previous studies, the main contributions of this study are followed:

- Focusing on a different level of the analysis. Compared to the macro level of metropolis of the previous studies, this is an empirical study focus on the level of neighborhoods.

- Classifying residents' travel into 3 different types for respective discussion. On account of different travel purposes, residents' travel is classified as commuter (go-to-work) travel, utilitarian (go-to-store) travel and recreational (strolling) travel. The survey questionnaire is designed corresponding to 3 travel types.

- Conducting a targeted and referential study. The selected research samples are with relatively high population density and include a certain amount of blocks with gated forms, which are 
distinctive contemporarily in China. Meanwhile, it is referential for many cities with similar population density, parallel space environment and construction.

\section{Methodology and Modeling}

This paper takes 15 neighborhoods in the main city of Nanjing as an example to conduct an empirical study. The travel types are divided into three categories according to the purposes of the trip: commuter travel, utilitarian travel and recreational travel. The built environment attributes mainly include three dimensions of land use, road network system and transit facilities. This paper conducted questionnaire survey and field survey in the sample neighborhoods to obtain data related to residents' travel modes, socio-economic attributes and built environment. Correlation analysis model, multivariate logit regression model and unary linear regression model are applied. Firstly, a bivariate correlation model is established to analyze the correlation between residents' travel modes and each potential influential variable, so that the primary variables influencing travel modes can be screened out. Secondly, a multivariate logit regression model is established to deeply account for the influence of built environment attributes on resident' travel mode. The most significant attributes, which are defined as key significant attributes, of built environment are further re-screened out from three dimensions of land use, road network system and transit service. Thirdly, based on the scatter chart of the relationship between key built environment variables and residents' travel modes, the recommended values of the key built environment variables for neighborhoods which are conducive to residents' low-carbon travel are proposed according to the linear relationship.

As the following flowchart (Figure 1) shows, the modeling specification includes three steps.

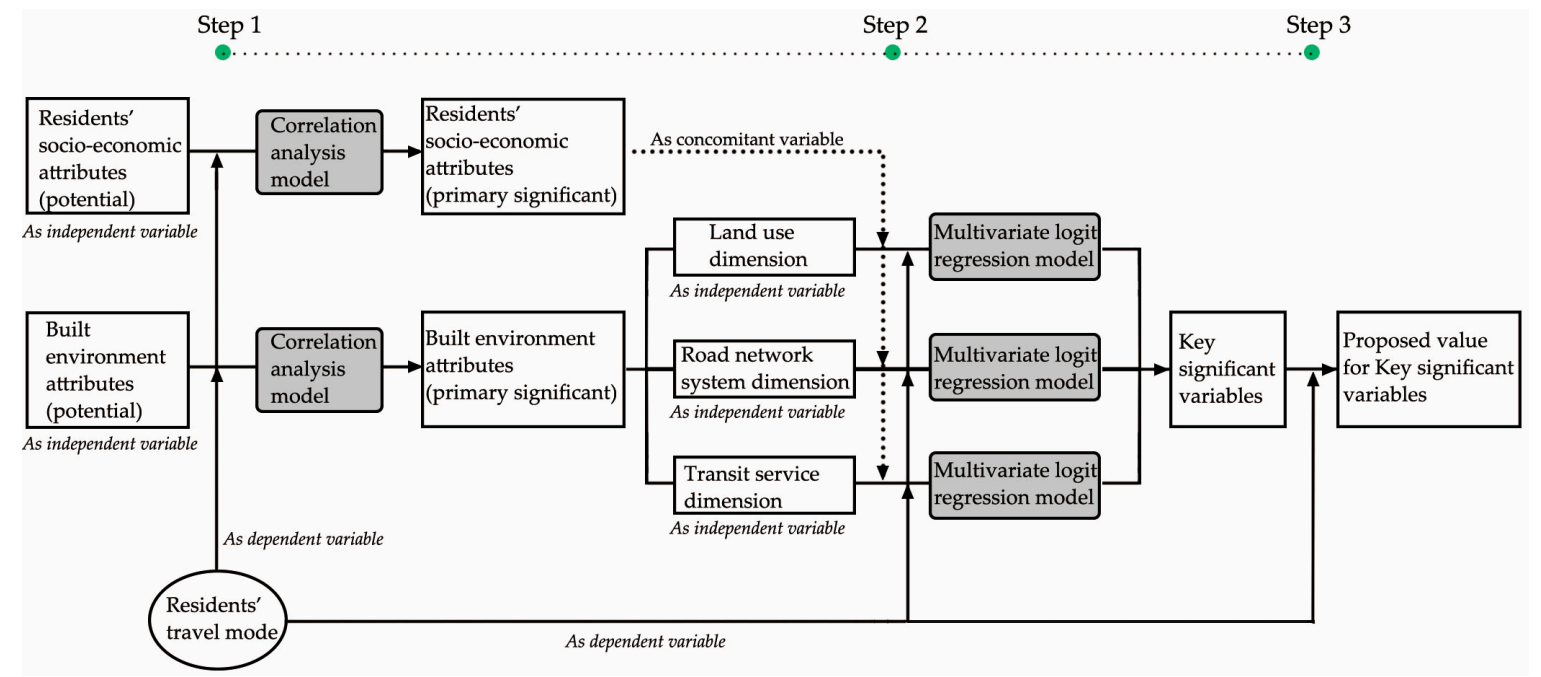

Figure 1. The flowchart of modeling specification.

Step 1. A correlation analysis model is used to preliminarily screen out the primary significant attributes. Potential influential attributes which are likely to have an impact on residents' travel are numerous and various. To make a primary and comprehensive screen of these potential attributes, a correlation analysis model is applied. The correlation analysis can be used to measure the relationship between two continuous variables, and can focus on the intensity and direction of the linear relationship between the two variables. In this paper, Pearson correlation analysis in SPSS software is applied to establish the bivariate correlation model which respectively combines the share of low-carbon travel of three purposes, the share of low-carbon travel overall with the residents' socio-economic attributes and the built environment attributes. Then the independent variables that have a significant impact on residents' low-carbon travel are selected. It also determines whether these significant variables are 
positively or negatively correlated with low-carbon travel. In addition, for these primary significant attributes, there is no horizontal comparison to identify the most significant attributes.

Step 2. Based on the primary significant attributes in Step1, a multivariate logit regression model is applied to re-screen out the key significant variables. In statistics, the logit regression can better describe the influence of different independent variables on the dependent variables. In Step1, the variables significantly influencing residents' travel mode have been preliminarily screened. However, there may be some mutual influences among the various significant variables. In order to make horizontal comparison between significant variables in each dimension and clearly define the key significant variables in each dimension of built environment, the multivariate logit regression method is used to conduct analysis for the variables from the dimensions of land use, road network system and transit service, with the significant socio-economic attributes as covariate variables. Assuming the basic multivariate logit regression model is:

$$
\mathrm{LN}\left(\mathrm{P}_{1} / \mathrm{P}_{2}\right)=\mathrm{f}\left(\mathrm{SD}_{\mathrm{i}}, \mathrm{BE}\right)=\beta_{0}+\beta_{1} \mathrm{X}_{1}+\beta_{2} \mathrm{X}_{2}+\ldots \ldots \beta_{\mathrm{i}} \mathrm{X}_{\mathrm{i}}+\mathrm{u}_{0}, \quad \mathrm{i}=1,2,3 \ldots \ldots \mathrm{N}
$$

In the formula, $\mathrm{P}_{1} / \mathrm{P}_{2}$ represents the odds ratio of the low-carbon travel mode and the motorized travel mode in the total $\mathrm{N}$ trips overall (including commuter travel, utilitarian travel and recreational travel) of residents surveyed; $\mathrm{SD}_{\mathrm{i}}$ indicates the socio-economic attribute variables of residents; $\mathrm{BE}_{\mathrm{i}}$ represents the variables of the built environment; $\beta_{0}$ is a constant term and $\beta_{1} ; \beta_{2} \ldots \ldots \beta_{i}$ are coefficients.

Step 3. Based on the key significant attributes in Step 2, a unary linear regression model is used to propose recommended values for them. In statistics, the linear regression analysis can describe the relationship between two continuous variables. Besides, the regression equation variables are estimated in order to achieve the purpose of prediction. In this study, the scatter plot of the share of low-carbon travel overall and each key significant variable of residential built environment as well as the linear regression model are used to explore the relationship between the built environment attributes and residents' low-carbon travel. Moreover, the recommended values are proposed for the key significant variables which are conducive to residents' low-carbon travel.

Taking the proportion $\mathrm{Pi}$ of the low-carbon travel in commuting travel, utilitarian travel, recreational travel as well as the overall travel as the dependent variable, the key indicator $X_{i}$ of the built environment is regarded as the independent variable to establish a linear regression equation. Assuming the basic linear regression model is:

$$
P_{i}=f\left(X_{i}\right)=\beta_{0}+\beta_{1} X_{i}+u_{0}, \quad I=1,2,3 \ldots 15
$$

In the formula, $P_{i}$ represents the share of low-carbon travel in neighborhood $i$, which is the dependent variable; $X_{i}$ represents a variable of the built environment of sample neighborhood $i$, which is an independent variable; $\beta_{0}$ is the constant term; $\beta_{1}$ is the coefficient.

\section{Design of Survey}

\subsection{Overview of the Research Area}

Nanjing, the capital city of Jiangsu Province, is one of the core cities in the Yangtze River Delta and the second largest city in the east China after Shanghai (Figure 2). Nanjing has a long history, and it used to be the capital of China in ten dynasties. Since the founding of the People's Republic of China, the urban area of Nanjing has undergone an expanding process of urbanization. In the early days after the founding of new China, Nanjing still continued its ancient layout. The scope of the urban area was limited within the Ming City Wall. In the 1990s, the growing population overwhelmed the old city. In order to alleviate the population pressure, the urban area has grown out of the limitation of the old city walls. The scope of the urban area is expanding and gradually developing into Longjiang Area, Hexi Area and Xianlin Area, forming the spatial layout of multi-district development. The construction including 
demolition, reconstruction and renovation of old districts of Nanjing is in parallel, which preserves the traditional urban fabric to a certain extent and retains some historical features. The construction of the new urban area is gradually maturing, forming a new urban center and expanding the layout of urban area. The research area of this study includes the old urban area with traditional urban texture and the continuously developing new urban area in the past two or three decades.

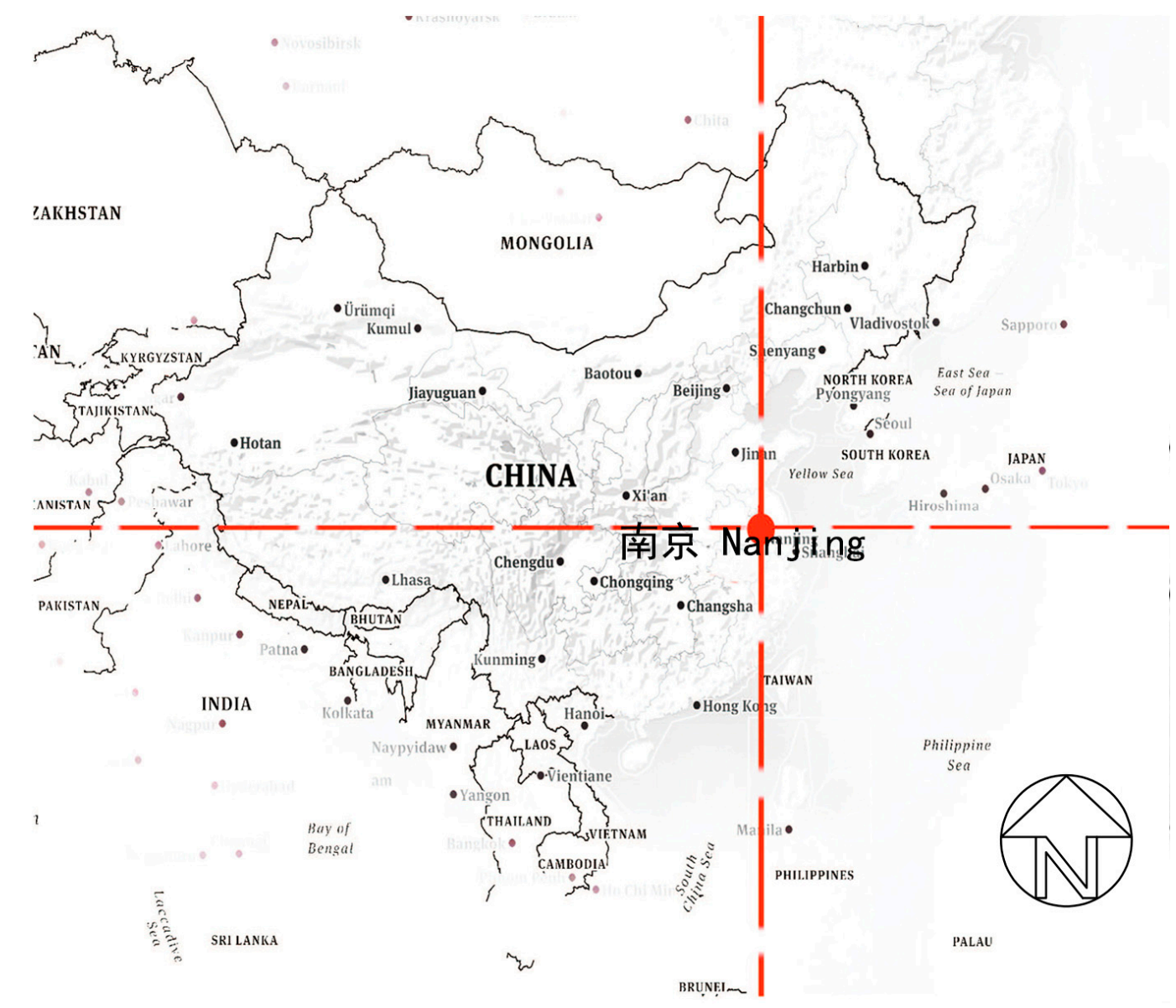

Figure 2. The location of Nanjing city in China.

\subsection{Selection of Research Sample}

In this study, the neighborhoods refer to the areas with different living populations, mainly including several residential communities. Taking Nanjing as an example, this paper selects the similar-sized neighborhoods in the main urban areas Xinjiekou, Longjiang and Hexi as the research samples (Figures 3 and 4), and the number of samples in each area is five. Among the three districts, Xinjiekou Area is located in the geographical center of Nanjing City. It is constantly updated with the times while maintaining the characteristics of the traditional blocks and has gradually developed into an important commercial and financial center with high degree of mixed land use and road network density. The residential blocks are widely distributed in the age of 1970s, 1980s, 1990s and 2000s, and most of them are open type. A small number of residential blocks built after 2000 are gated type. An additional note here is that in China the concept of gated blocks means blocks enclosed by fencings, walls or other structures, with entrance guard set. Enclosure management is implemented to prevent people who are not residents living in this gated blocks entering. Gated type has been popular in blocks in China since 2000. The concept of open blocks means the opposite. Located in the west of the city wall of the old districts, Longjiang Area was developed in order to alleviate the urban population pressure caused by the rapid growth of the old city in the 1990s. It is with lower mixed degree of land 
use and road network density compared Xinjiekou. Residential blocks are mostly semi-open mode. The Hexi Area is located in the southwest of the old city. It is a new city whose construction began from 2000. Relatively speaking, the urban roads are wide and the living blocks are large in scale and communities are mostly enclosed. To conclude, the three areas show different spatial forms and the built environment is different to some extent which meets the requirements of the investigation target.

The scale of sample neighborhoods in the survey is between $0.6 \mathrm{~km}^{2}$ and $1.8 \mathrm{~km}^{2}$, and the building area for residential functions is above $50 \%$. The scope of neighborhoods per unit sample is based on the natural boundaries of major or minor urban roads, natural boundaries like rivers, and it takes a 10-min walking distance of $800 \mathrm{~m}$ and an effective coverage of transit station of $500 \mathrm{~m}$ as the reference for determining the radius of the survey area, of which $500 \mathrm{~m}$ is based on the definition of relative measures in the Code for Transport Planning on Urban Road [24].

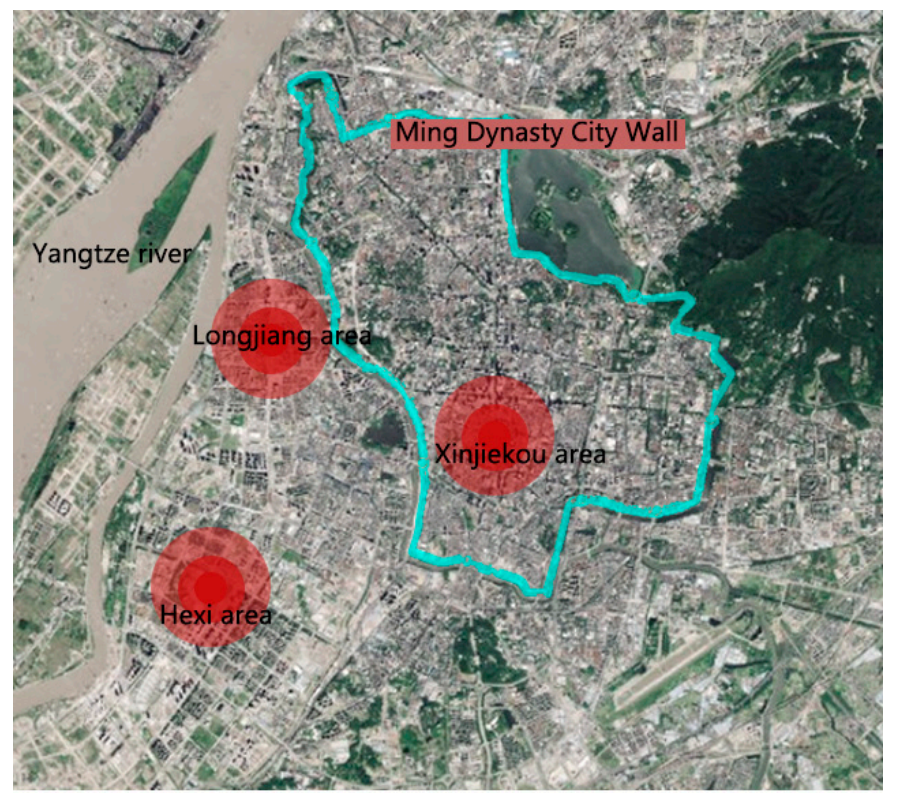

Figure 3. The location of the research areas in Nanjing.

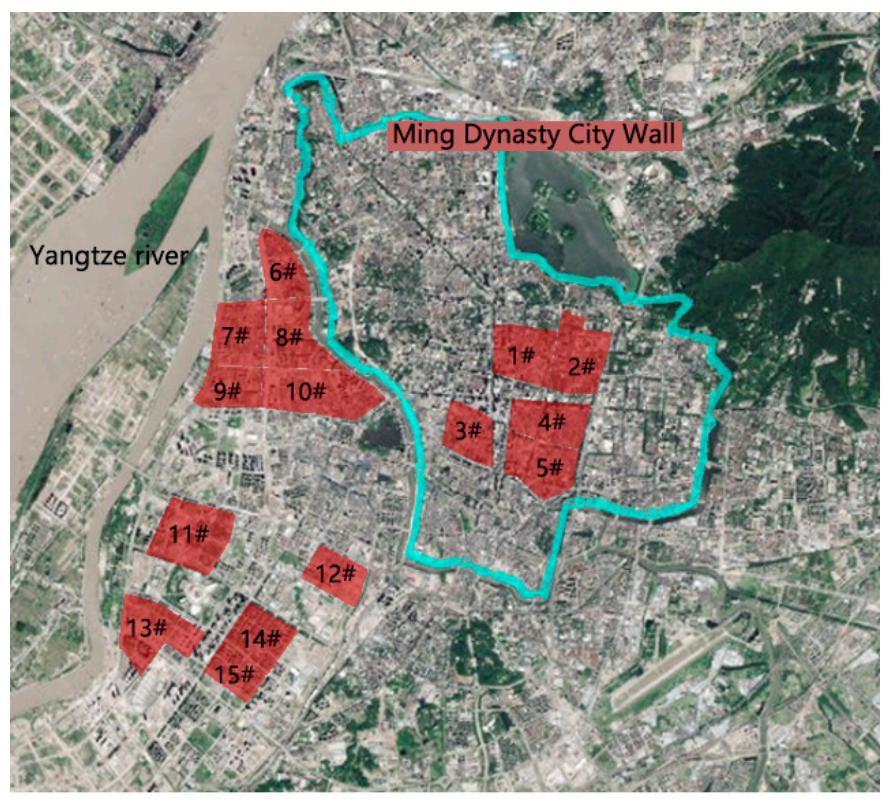

Figure 4. The location of the research neighborhoods in Nanjing. 


\subsection{Content of Survey}

The survey mainly includes two aspects. One aspect is survey of residents' socio-economic attributes and residents' travel. The other aspect is survey of the residential built environment attributes.

\subsubsection{Residents' Socio-Economic Attributes and Travel Survey}

The research group consisted of 45 undergraduates and graduates. On average, three surveyors were arranged in each sample neighborhood. In this study, the simple random sampling [25] is applied for questionnaire survey. In the practice of urban design, when it comes to a huge quantity of research samples to survey or interview, the simple random sampling is an efficient approach. To minimize the subjectivity committed during the selection of research object is necessary. Before the conduction of survey and field research, the group leader had made sufficient explanation to every surveyor about the task and points worthy of notice, including the selection of research site, the rationalization of sex proportion and age proportion of the investigated et al. Using the works of Wei et al. [7], Chen et al. [23] and Handy et al. [26] as reference, the questionnaire was designed and adapted to the needs of this study. Referring to previously applied questionnaires makes broad considerations predominating over narrow on data to collect and measures reliability of the collected data by making comparison of the results with other studies. Random surveys were conducted in the form of face-to-face interviews. The response of the respondents is recorded according to the option of multiple-choice questions in the survey questionnaire. Due to the fact that travel behavior of different purposes tends to occur at different time periods, in order to ensure the diversity and randomness of the residents surveyed, the survey was conducted in two days, of which one day was selected in good weather on a normal working day at dusk time, while the other day was selected on the weekend. The respondents are residents living in these 15 sample neighborhoods, and the questionnaires were distributed evenly throughout the sample neighborhoods, including front spaces of residential buildings, entrances of blocks with high visitors flow rate, public space for rest, stores along the street and so on. The proportionality of survey time period, the diversity of the investigated and the spread around research sites are the basics of a balanced and randomized survey.

A total of 1800 questionnaires were sent out by the research group (120 in each sample), and 1622 valid questionnaires were finally sorted out. The questions are the formation of multi-choice, and the questionnaire includes travel data and basic information of residents.

(1) According to travel purposes, the travel data collection of residents is divided into commuter travel mode, utilitarian travel mode and recreational travel mode. The most frequently chosen travel mode is recorded corresponding to different travel purposes. The options of travel modes include public transit, non-motor vehicles, walking and motor vehicles, and the first three are low-carbon travel modes.

(2) Data collection of residents' socio-economic attributes is at both the personal and family level, including residents' gender, age, educational level, number of family members, household annual income status and home vehicle ownership and so on. Groupings of each socio-economic attributes are set according to some standard. For example, groupings of age are divided into four options. The 6-18 are juveniles who are not allowed to drive by law. The 19-32 are the youth, most of whom have not given birth. The 33-60 are the middle-aged, most of whom have given birth. Over 60 are the aged people, most of whom have retired. Considering that the average income of urban residents in Nanjing in 2017 is about $¥ 50,000$ [27], groupings of annual household income are divided into four options, according to families of one person, families of two persons, families of three persons, and families of four persons.

\subsubsection{Research of Built Environment Attributes}

In the built environment of neighborhoods, land use, road system and transit facilities may directly affect residents' job-housing distance and workplace, the quality of travel environment and travel 
convenience, which further influence residents' travel modes. In order to examine the relationship between the built environment of these three dimensions and residents' travel modes, it requires selecting the potential variables from the built environment for investigation and survey so as to prepare the data for subsequent research and analysis. The relevant data are mainly obtained from Nanjing topographic maps and land use status available from Nanjing Urban Planning Compilation and Research Center, and combined with the field observations and measurements.

(1) The data of land use dimension are collected from the three variables: the mixed degree of land use, floor space ratio and building coverage.

- Mixed degree of land will be related to residents' job-housing distance, daily utilitarian, recreational travel distance and other aspects. We classify building functions into four types: residential buildings, administrative and public service buildings, commercial and business facilities, and business office buildings. The calculation formula is shown as follows $[11,28,29]$ :

$$
\text { Landusemixi }=\frac{-\sum_{\mathrm{K}=1}^{\mathrm{K}} \mathrm{P}_{\mathrm{k}, \mathrm{i}} \ln \left(\mathrm{P}_{\mathrm{k}, \mathrm{i}}\right)}{\ln (\mathrm{K}, \mathrm{i})}
$$

In the formula, $\mathrm{K}$ represents the number of land use types in neighborhood $\mathrm{i}$, and $\mathrm{P}_{\mathrm{k}, \mathrm{i}}$ stands for the floor area proportion of the Kth land use type in neighborhood i. High value often indicates the high mixed degree of land use.

- Floor space ratio. It is the indicator that reflects the intensity of land use, which is calculated as:

$$
\text { Floor space ratio }=\frac{S_{t b, i}}{S_{n, i}}
$$

In the formula, $\mathrm{S}_{\mathrm{tb}, \mathrm{i}}$ represents the total building floor area in neighborhood $\mathrm{i}$, and $\mathrm{S}_{\mathrm{n}, \mathrm{i}}$ stands for the area of neighborhood $\mathrm{i}$.

- Building coverage. The formula is:

$$
\text { Building coverage }=\frac{S_{b d, i}}{S_{n, i}}
$$

In the formula, $\mathrm{S}_{\mathrm{bd}, \mathrm{i}}$ represents the gross building area in neighborhood $\mathrm{i}$, and $\mathrm{S}_{\mathrm{n}, \mathrm{i}}$ stands for the area of neighborhood $i$.

(2) In terms of the road network system dimension, data are collected from three variables: the road network connectivity, road network density, and road area ratio.

- Road network connectivity is used to measure the accessibility of roads. There are different ways to calculate this index [30]. This paper refers to the method used by Wei [7], which marks the crossing intersection 0.8 , " $\mathrm{T}$ " crossing 0.6 and end crossing 0.2 . The formula is:

$$
\text { Road network connectivity }=\frac{\mathrm{Sc}, \mathrm{i}}{\mathrm{S}_{\mathrm{n}, \mathrm{i}}}
$$

In the formula, $S_{c, i}$ represents the total scores of the crossings, and $S_{n, i}$ stands for the area of neighborhood i.

- Road network density reflects the overall accessibility of the road and the degree of density, which is calculated as:

$$
\text { Road network density }=\frac{\mathrm{Li}}{\mathrm{S}_{\mathrm{n}, \mathrm{i}}}
$$

In the formula, $L_{i}$ represents the total length of the road in neighborhood $i$, and $S_{n, i}$ stands for the area of neighborhood i. 
- Road area ratio refers to the ratio of road area to neighborhood within its range, which is calculated as:

$$
\text { Road area ratio }=\frac{\mathrm{Sa}, \mathrm{i}}{\mathrm{S}_{\mathrm{n}, \mathrm{i}}}
$$

In the formula, $S_{a, i}$ represents the road area in neighborhood $i$, and $S_{n, i}$ stands for the area of neighborhood i.

(3) In transit facilities dimension, data of the variable transit station coverage are collected.

- the transit station coverage is selected to measure the distribution of public facilities and service levels, which is calculated as follows:

$$
\text { Transit station coverage }=\frac{\mathrm{Stsc}, \mathrm{i}}{\mathrm{S}_{\mathrm{n}, \mathrm{i}}}
$$

In the formula, $S_{t s c, i}$ represents the transit station service coverage area in neighborhood $i$, and $S_{n, i}$ stands for the area of neighborhood i. In this research, public transport stations include bus stops and rail transit stations. The 300-m and 500-m radius are considered as the yardstick of the service range of bus stops in the Code for Transport Planning on Urban Road [24]. Considering that most of the blocks in China are gated type and the block size is too large, this study selects 300 meters as a measure of the coverage radius. Taking the actual road network morphology around the station site into consideration, GIS tools are used for calculating this variable.

\section{Data Statistics and Preliminary Analysis}

\subsection{Residents' Travel Data}

In order to carry out a more complete and detailed description of the residents' travel, this paper divides the residents' travel into three types according to different purposes, including commuter travel, utilitarian travel and recreational travel. In the questionnaires, questions and options are set for different travel modes under each travel purpose. After the statistics of collected questionnaires, the number of residents choosing low-carbon travel modes is calculated in each sample neighborhood corresponding to each travel purpose. For each travel purpose, dividing the number of low-carbon travel residents by the total quantity of the collected questionnaires, equals to the share of low-carbon travel of commuter travel $\mathrm{P}_{\mathrm{CT}}$, utilitarian travel $\mathrm{P}_{\mathrm{UT}}$ and recreational travel $\mathrm{P}_{\mathrm{RT}}$. Likewise, dividing the number of residents' choosing low-carbon travel modes of three travel types totally by the total quantity of trips of three travel types equals to the share of low-carbon travel overall $\mathrm{P}_{\mathrm{OT}}$, accounting for the overall travel.

Based on the preliminary statistics, the statistical histograms of the proportion of low-carbon travelers under three travel purposes in 15 sample neighborhoods of three areas, are shown as follows (Tables 1 and 2, Figure 5a,b).

Tables 1 and 2 show that no matter what the purpose of travel is or the overall travel, the descending order of the share of low-carbon travel in three major areas is Xinjiekou Area, Longjiang Area and Hexi Area. This shows that there may be some potential variables among the socio-economic attributes of different groups of residents and different built environment that have some impact on residents' travel mode, which also illustrates the significance of choosing sample from these 3 different areas. It is noteworthy that the share of low-carbon travel in Xinjiekou Area reached a relatively high level, above $80 \%$. According to the official data in Nanjing Transport Annual Report 2015, the share of residents who choose low-carbon travel modes in main districts in Nanjing is about $82.9 \%$ [31], as Figure 6 shows. The residents' travel data of this study is close to the official data and is credible to some extent. 
Table 1. Share of low-carbon travel residents of three areas.

\begin{tabular}{ccccc}
\hline Area & Commuter Travel & Utilitarian Travel & Recreational Travel & Overall Travel \\
\hline Xinjiekou & 0.853 & 0.861 & 0.808 & 0.842 \\
Longjiang & 0.756 & 0.821 & 0.738 & 0.769 \\
Hexi & 0.669 & 0.778 & 0.721 & 0.724 \\
\hline
\end{tabular}

Table 2. Share of low-carbon travel residents of 15 neighborhoods.

\begin{tabular}{ccccc}
\hline Neighborhood & Commuter Travel & Utilitarian Travel & Recreational Travel & Overall Travel \\
\hline NO. 1 & 0.830 & 0.856 & 0.750 & 0.813 \\
NO. 2 & 0.925 & 0.892 & 0.908 & 0.911 \\
NO. 3 & 0.805 & 0.788 & 0.742 & 0.803 \\
NO. 4 & 0.867 & 0.925 & 0.833 & 0.858 \\
NO. 5 & 0.836 & 0.843 & 0.809 & 0.827 \\
NO. 6 & 0.842 & 0.867 & 0.798 & 0.830 \\
NO. 7 & 0.532 & 0.743 & 0.664 & 0.650 \\
NO. 8 & 0.733 & 0.800 & 0.603 & 0.736 \\
NO. 9 & 0.804 & 0.887 & 0.841 & 0.810 \\
NO. 10 & 0.867 & 0.808 & 0.782 & 0.819 \\
NO. 11 & 0.533 & 0.764 & 0.682 & 0.661 \\
NO. 12 & 0.704 & 0.813 & 0.807 & 0.777 \\
NO. 13 & 0.792 & 0.755 & 0.642 & 0.732 \\
NO. 14 & 0.690 & 0.839 & 0.776 & 0.770 \\
NO. 15 & 0.624 & 0.718 & 0.700 & 0.679 \\
\hline
\end{tabular}

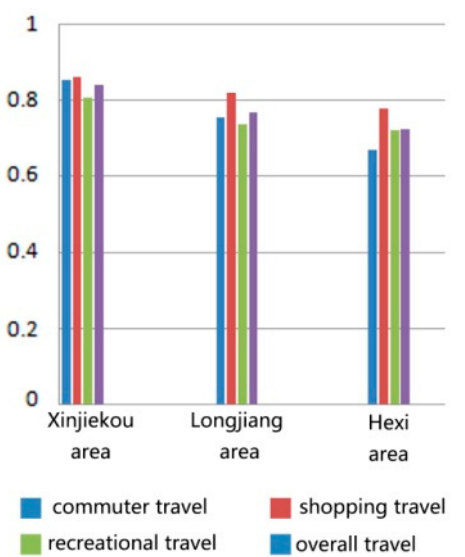

(a)

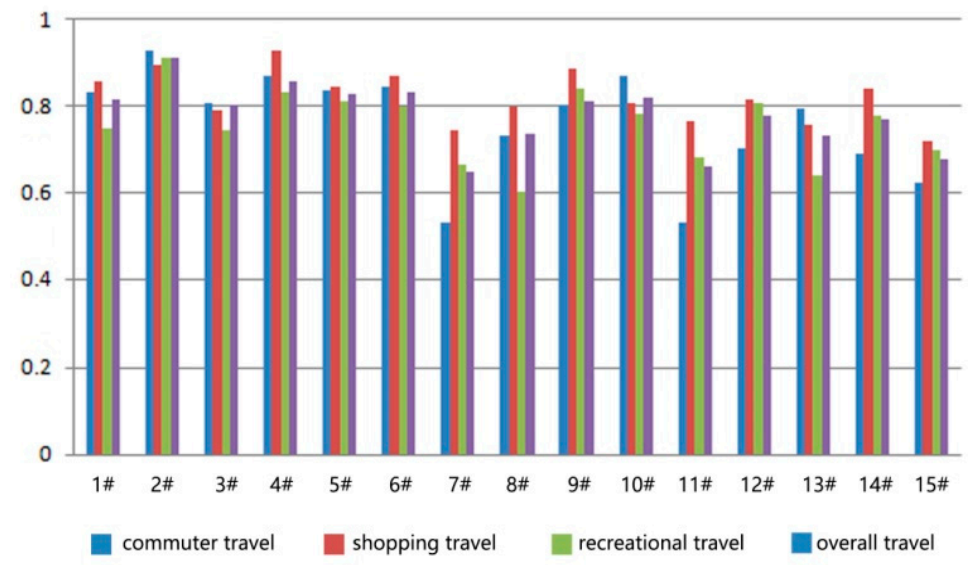

(b)

Figure 5. (a) Share of low-carbon travel residents of three areas; (b) Share of low-carbon travel residents of 15neighborhoods. 


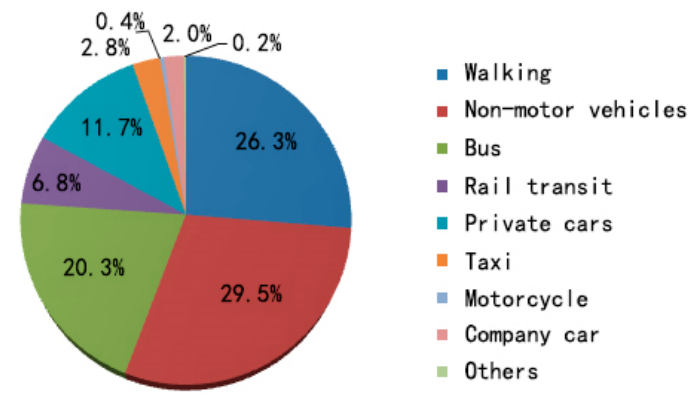

Figure 6. Proportion of residents' travel mode in main districts in Nanjing 2014.

\subsection{Residents' Socio-Economic Attributes Data}

Tables 3 and 4 show the proportions of residents' socio-economic attributes in 15 sample neighborhoods and three areas. The data of each attribute are classified by area and the preliminary statistics are made (Figure 7). Figure 7a,b shows that the gender proportion and age proportion of residents surveyed in three areas are similar to each other, and the gender proportion is close to 1:1, the proportion of people aging from $19-32$ and $33-60$ accounted for $50 \%$ and $35 \%$ respectively. It can be seen from Figure 7c,e,f that among the residents surveyed, the educational level, annual household income and family car ownership in Hexi Area are generally higher than those in Longiiang Area and Xinjiekou Area. Figure 7d shows that the population of each family of the three areas is close to each other. Among them, families of two people account for a large proportion in Hexi Area, which is probably because it is located in CBD where there are more young people.

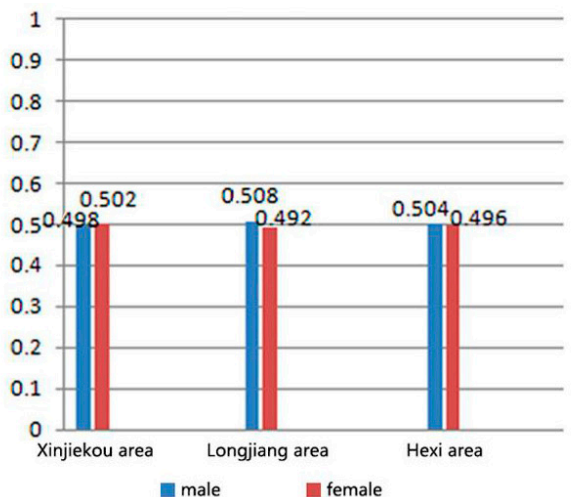

(a)

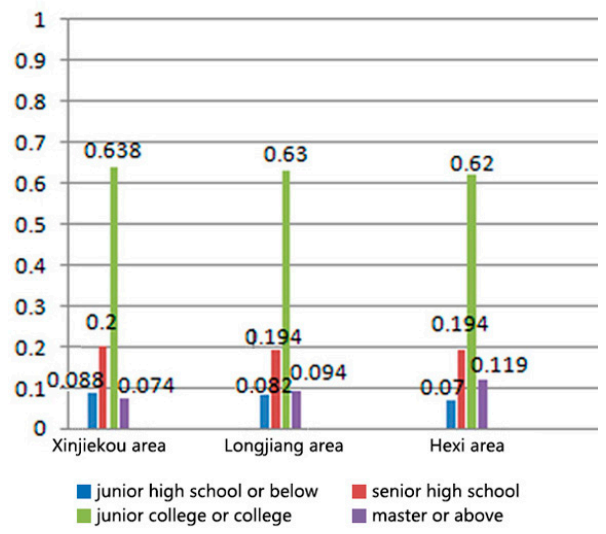

(c)

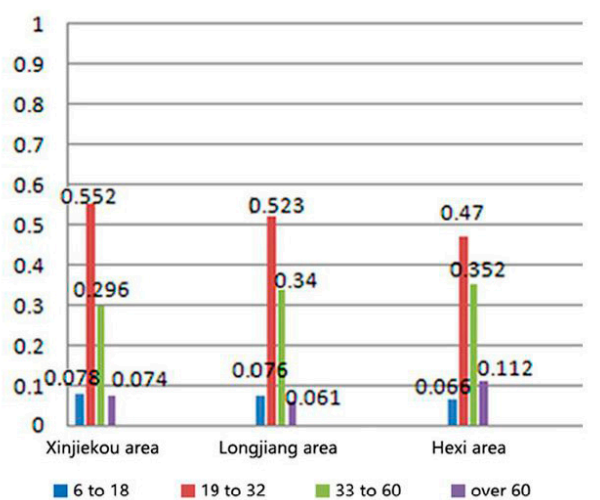

(b)

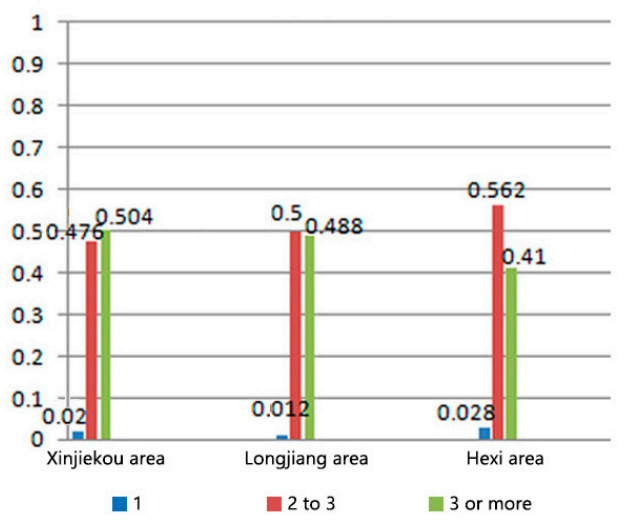

(d)

Figure 7. Cont. 


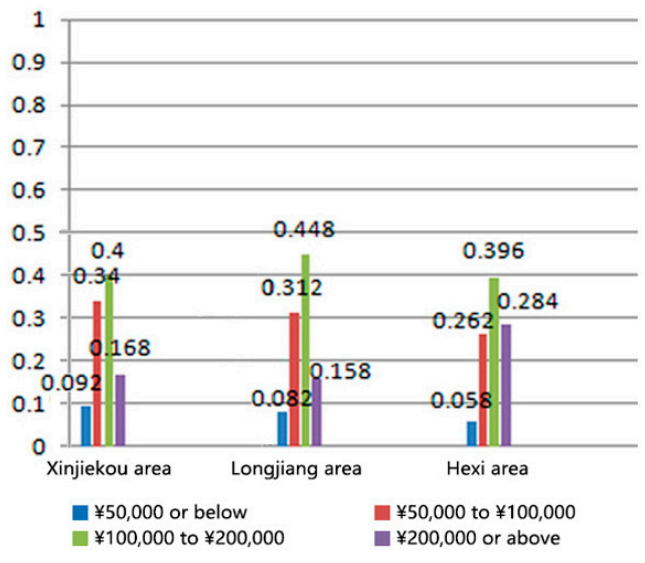

(e)

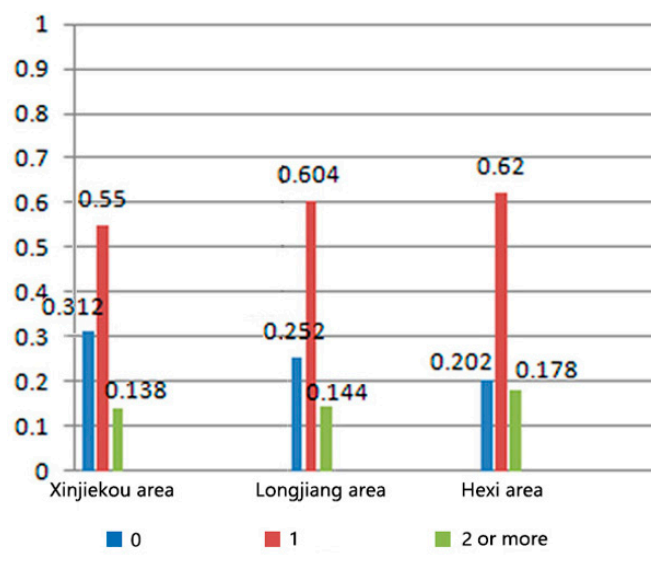

(f)

Figure 7. (a) Proportion of surveyed residents' sex of three areas; (b) Proportion of surveyed residents' age of three areas; (c) Proportion of surveyed residents' educational attainment; (d) Proportion of surveyed residents' family population; (e) Proportion of surveyed residents' annual household income; (f) Proportion of surveyed residents' car ownership.

Table 3. Proportion of the of the surveyed residents' socio-economic attributes of 15 neighborhoods.

\begin{tabular}{|c|c|c|c|c|c|c|c|c|c|c|}
\hline \multirow[b]{2}{*}{ Neighborhood } & \multicolumn{2}{|c|}{ Sex Ratio } & \multicolumn{4}{|c|}{ Age Ratio } & \multicolumn{4}{|c|}{ Educational Attainment Ratio } \\
\hline & Male & Female & 6 to 18 & 19 to 32 & 33 to 60 & Over 60 & $\begin{array}{l}\text { Junior High } \\
\text { School or } \\
\text { Below }\end{array}$ & $\begin{array}{l}\text { Senior } \\
\text { High } \\
\text { School }\end{array}$ & $\begin{array}{l}\text { Junior } \\
\text { College or } \\
\text { College }\end{array}$ & $\begin{array}{c}\text { Master or } \\
\text { Above }\end{array}$ \\
\hline NO.1 & $48 \%$ & $52 \%$ & $12 \%$ & $41 \%$ & $31 \%$ & $17 \%$ & $15 \%$ & $18 \%$ & $56 \%$ & $11 \%$ \\
\hline NO. 2 & $48 \%$ & $52 \%$ & $2 \%$ & $50 \%$ & $44 \%$ & $4 \%$ & $6 \%$ & $22 \%$ & $60 \%$ & $12 \%$ \\
\hline NO.3 & $51 \%$ & $49 \%$ & $6 \%$ & $48 \%$ & $43 \%$ & $3 \%$ & $7 \%$ & $24 \%$ & $61 \%$ & $8 \%$ \\
\hline NO.6 & $52 \%$ & $48 \%$ & $5 \%$ & $57 \%$ & $32 \%$ & $6 \%$ & $9 \%$ & $21 \%$ & $68 \%$ & $2 \%$ \\
\hline NO.7 & $49 \%$ & $51 \%$ & $6 \%$ & $57 \%$ & $29 \%$ & $8 \%$ & $13 \%$ & $17 \%$ & $58 \%$ & $12 \%$ \\
\hline NO.8 & $49 \%$ & $51 \%$ & $9 \%$ & $57 \%$ & $24 \%$ & $10 \%$ & $0 \%$ & $18 \%$ & $71 \%$ & $11 \%$ \\
\hline NO.9 & $47 \%$ & $53 \%$ & $8 \%$ & $53 \%$ & $31 \%$ & $8 \%$ & $12 \%$ & $26 \%$ & $58 \%$ & $4 \%$ \\
\hline NO.10 & $52 \%$ & $48 \%$ & $11 \%$ & $52 \%$ & $32 \%$ & $5 \%$ & $10 \%$ & $18 \%$ & $64 \%$ & $8 \%$ \\
\hline NO.11 & $48 \%$ & $52 \%$ & $6 \%$ & $52 \%$ & $34 \%$ & $8 \%$ & $6 \%$ & $15 \%$ & $65 \%$ & $14 \%$ \\
\hline
\end{tabular}

Table 4. Proportion of the of the surveyed residents' socio-economic attributes of 15 neighborhoods.

\begin{tabular}{|c|c|c|c|c|c|c|c|c|c|c|}
\hline \multirow[b]{2}{*}{ Neighborhood } & \multicolumn{3}{|c|}{ Family Population Ratio } & \multicolumn{4}{|c|}{ Annual Household Income Ratio } & \multicolumn{3}{|c|}{ Car Ownership Ratio } \\
\hline & 1 & 2 to 3 & 3 or More & $\begin{array}{c}¥ 50,000 \text { or } \\
\text { Below }\end{array}$ & $\begin{array}{c}¥ 50,000 \text { to } \\
¥ 100,000\end{array}$ & $\begin{array}{c}¥ 100,000 \text { to } \\
¥ 200,000\end{array}$ & $\begin{array}{l}¥ 200,000 \\
\text { or Above }\end{array}$ & 0 & 1 & 2 or More \\
\hline NO.1 & $0 \%$ & $49 \%$ & $51 \%$ & $15 \%$ & $39 \%$ & $27 \%$ & $19 \%$ & $32 \%$ & $55 \%$ & $13 \%$ \\
\hline NO.2 & $3 \%$ & $52 \%$ & $45 \%$ & $4 \%$ & $27 \%$ & $50 \%$ & $19 \%$ & $22 \%$ & $58 \%$ & $20 \%$ \\
\hline NO.3 & $1 \%$ & $59 \%$ & $50 \%$ & $6 \%$ & $30 \%$ & $53 \%$ & $11 \%$ & $21 \%$ & $69 \%$ & $10 \%$ \\
\hline NO.4 & $2 \%$ & $56 \%$ & $42 \%$ & $4 \%$ & $32 \%$ & $50 \%$ & $14 \%$ & $20 \%$ & $60 \%$ & $20 \%$ \\
\hline NO.5 & $0 \%$ & $44 \%$ & $56 \%$ & $12 \%$ & $28 \%$ & $44 \%$ & $16 \%$ & $31 \%$ & $60 \%$ & $9 \%$ \\
\hline NO.6 & $1 \%$ & $42 \%$ & $57 \%$ & $10 \%$ & $48 \%$ & $37 \%$ & $5 \%$ & $28 \%$ & $59 \%$ & $13 \%$ \\
\hline NO.7 & $0 \%$ & $47 \%$ & $53 \%$ & $8 \%$ & $39 \%$ & $35 \%$ & $18 \%$ & $34 \%$ & $50 \%$ & $16 \%$ \\
\hline NO.8 & $5 \%$ & $44 \%$ & $51 \%$ & $7 \%$ & $31 \%$ & $51 \%$ & $11 \%$ & $28 \%$ & $59 \%$ & $13 \%$ \\
\hline NO.9 & $2 \%$ & $51 \%$ & $47 \%$ & $6 \%$ & $22 \%$ & $45 \%$ & $27 \%$ & $37 \%$ & $46 \%$ & $17 \%$ \\
\hline NO.10 & $2 \%$ & $54 \%$ & $44 \%$ & $15 \%$ & $30 \%$ & $32 \%$ & $23 \%$ & $29 \%$ & $61 \%$ & $10 \%$ \\
\hline NO.11 & $1 \%$ & $56 \%$ & $43 \%$ & $5 \%$ & $28 \%$ & $35 \%$ & $32 \%$ & $17 \%$ & $64 \%$ & $19 \%$ \\
\hline NO.12 & $4 \%$ & $63 \%$ & $33 \%$ & $7 \%$ & $27 \%$ & $33 \%$ & $33 \%$ & $18 \%$ & $62 \%$ & $20 \%$ \\
\hline NO.13 & $2 \%$ & $71 \%$ & $27 \%$ & $4 \%$ & $19 \%$ & $45 \%$ & $32 \%$ & $24 \%$ & $57 \%$ & $19 \%$ \\
\hline NO.14 & $3 \%$ & $39 \%$ & $12 \%$ & $8 \%$ & $28 \%$ & $44 \%$ & $20 \%$ & $26 \%$ & $61 \%$ & $13 \%$ \\
\hline NO.15 & $4 \%$ & $52 \%$ & $44 \%$ & $5 \%$ & $29 \%$ & $41 \%$ & $25 \%$ & $16 \%$ & $66 \%$ & $18 \%$ \\
\hline
\end{tabular}




\subsection{Built Environment Characteristic Data of Neighborhoods}

Figure 8 is topographic maps of 15 neighborhoods, which shows the space forms of them. Tables 5-7 are the statistics of built environment characteristic variables of neighborhoods in Xinjiekou Area, Longjiang Area and Hexi Area. In the dimension of land use, the average values of the three variables, land use mix, floor space ratio and building coverage are arranged in descending order of Xinjiekou Area, Longjiang Area and Hexi Area. In the dimension of road network system, the average valuse of road network connectivity and road network density in Xinjiekou is higher than that in Longiiang Area, which is higher than that in Hexi. There is not so much difference of the road area ratio in these three areas. In the dimension of transit facilities, the average coverage of transit stations in Hexi Area is the largest. The average value of Xinjiekou Area and Longjiang Area is close to each other, and the distribution of transit stations in each sample area is fine. The average transit coverage with the radius of $300 \mathrm{~m}$ in these three areas is more than $73 \%$ (Figure 9).

The data show that there are considerable differences in the built environment attributes of the three areas, which may be related to the location of cities, the construction and the planning concepts at that time: Xinjiekou Area is located in Nanjing City Center with high population density, compact land use and well-equipped with commercial, office and public service facilities. The continued road network construction largely preserves the traditional urban fabric with relatively narrow roads and small-scale neighborhoods. The transit facilities are complete. Longjiang Area is developed and built to relieve the pressure of population growth in the old city. The intensity of land development is enhanced and the proportion of residential functions is increased. Most of the residential buildings are the form of multi-storey residential building and the form of tower-type high-rise residential building. Compared with the Xinjiekou Area, the road area ratio of Longjiang Area is close and the width of road network is widened. Meanwhile, the road network density is reduced and the block size is also relatively larger. There are convenient public transport facilities in this area. Hexi Area is the new city planned in the 2000s. The building form is mainly high-rise and super-high-rise. So the buildings cover relatively small areas. For example, the average density of the surveyed buildings is only $16 \%$. The road planning is inclined to be 'auto-oriented' so the road is extremely wide. The average width of NO.11 Neighborhood is up to $37.2 \mathrm{~m}$, coupled with the correspondingly low road network density and large-scale blocks. The transit facilities are relatively accessible.

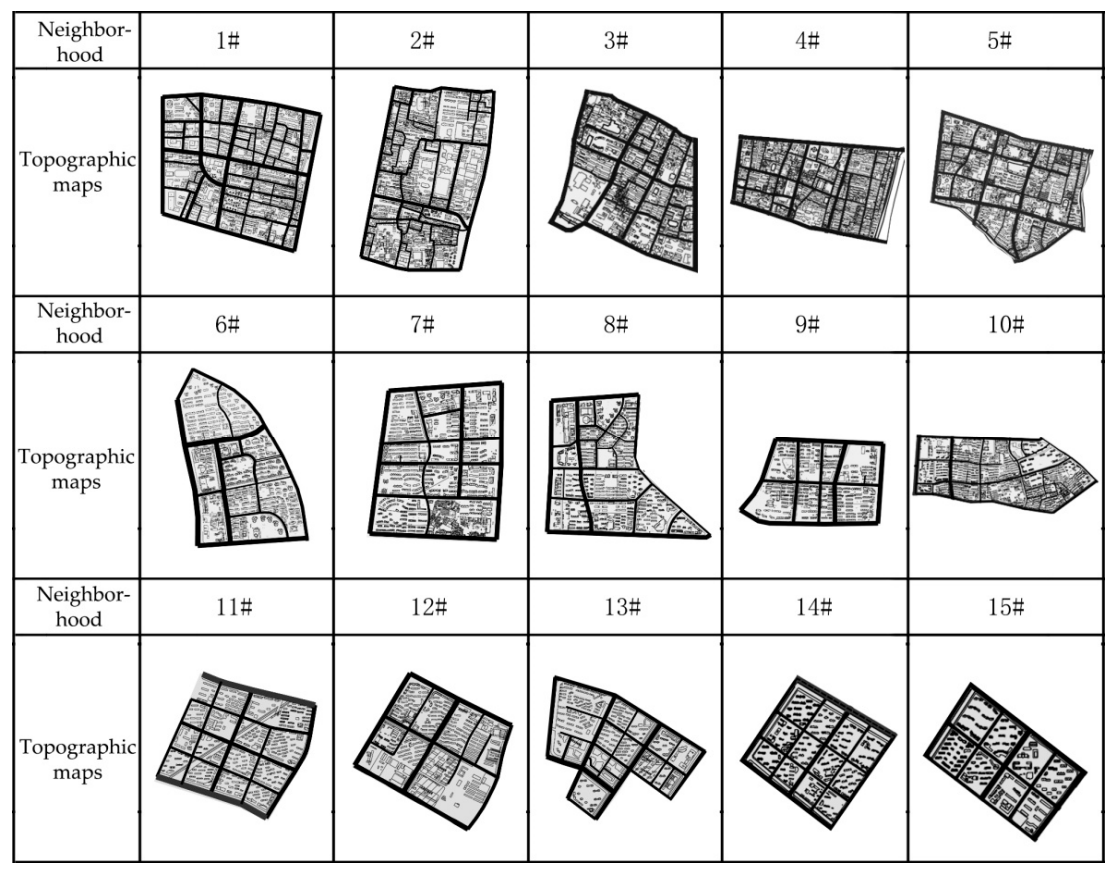

Figure 8. Topographic maps of 15 neighborhoods. 
Table 5. Variables of the of the built environment attributes of 5 neighborhoods in Xinjiekou Area.

\begin{tabular}{|c|c|c|c|c|c|c|c|c|c|}
\hline \multirow{2}{*}{ Area } & \multirow{2}{*}{ Neighborhood } & \multirow{2}{*}{$\begin{array}{l}\text { Neighborhood } \\
\text { Area }\left(\mathbf{k m}^{2}\right)\end{array}$} & \multicolumn{3}{|c|}{ Land Use Dimension } & \multicolumn{3}{|c|}{ Road Network System Dimension } & \multirow{2}{*}{$\begin{array}{c}\begin{array}{c}\text { Transit Facilities } \\
\text { Dimension }\end{array} \\
\begin{array}{c}\text { Coverage of the } \\
\text { Transit Station }(\%\end{array} \\
\end{array}$} \\
\hline & & & $\begin{array}{l}\text { Mixed Degree of } \\
\text { Land Use }\end{array}$ & $\begin{array}{c}\text { Floor Space } \\
\text { Ratio }\end{array}$ & $\begin{array}{c}\text { Building } \\
\text { Coverage (\%) }\end{array}$ & $\begin{array}{c}\text { Road Network } \\
\text { Connectivity (Scores) }\end{array}$ & $\begin{array}{c}\text { Road Network } \\
\text { Density }\left(\mathbf{k m} / \mathbf{k m}^{2}\right)\end{array}$ & $\begin{array}{l}\text { Road Area } \\
\text { Ratio (\%) }\end{array}$ & \\
\hline \multirow{6}{*}{ Xin-jiekou } & $1 \#$ & 1.17 & 0.864 & 2.55 & $27.0 \%$ & 57.4 & 15.5 & $40.0 \%$ & $84.7 \%$ \\
\hline & 2\# & 1.66 & 0.912 & 1.22 & $26.0 \%$ & 35.2 & 12.0 & $30.0 \%$ & $54.6 \%$ \\
\hline & 3\# & 0.87 & 0.889 & 2.05 & $32.0 \%$ & 42.3 & 13.6 & $34.0 \%$ & $92.5 \%$ \\
\hline & $4 \#$ & 1.10 & 0.844 & 2.29 & $38.0 \%$ & 48.4 & 15.1 & $31.0 \%$ & $65.5 \%$ \\
\hline & $5 \#$ & 1.23 & 0.788 & 2.11 & $32.0 \%$ & 32.2 & 11.9 & $28.0 \%$ & $75.0 \%$ \\
\hline & Mean & 1.21 & 0.859 & 2.04 & $31.0 \%$ & 43.1 & 13.6 & $33.0 \%$ & $75.0 \%$ \\
\hline
\end{tabular}

Table 6. Variables of the of the built environment attributes of 5 neighborhoods in Longjiang Area.

\begin{tabular}{|c|c|c|c|c|c|c|c|c|c|}
\hline \multirow{2}{*}{ Area } & \multirow{2}{*}{ Neighborhood } & \multirow{2}{*}{$\begin{array}{l}\text { Neighborhood } \\
\text { Area }\left(\mathbf{k m}^{2}\right)\end{array}$} & \multicolumn{3}{|c|}{ Land Use Dimension } & \multicolumn{3}{|c|}{ Road Network System Dimension } & \multirow{2}{*}{$\begin{array}{c}\begin{array}{c}\text { Transit Facilities } \\
\text { Dimension }\end{array} \\
\text { Coverage of the } \\
\text { Transit Station (\% }\end{array}$} \\
\hline & & & $\begin{array}{l}\text { Mixed Degree of } \\
\text { Land Use }\end{array}$ & $\begin{array}{c}\text { Floor Space } \\
\text { Ratio }\end{array}$ & $\begin{array}{c}\text { Building } \\
\text { Coverage (\%) }\end{array}$ & $\begin{array}{c}\text { Road Network } \\
\text { Connectivity (Scores) }\end{array}$ & $\begin{array}{c}\text { Road Network } \\
\text { Density }\left(\mathrm{km} / \mathrm{km}^{2}\right)\end{array}$ & $\begin{array}{l}\text { Road Area } \\
\text { Ratio (\%) }\end{array}$ & \\
\hline \multirow{6}{*}{ Long-jiang } & $6 \#$ & 0.90 & 0.667 & 1.80 & $26.0 \%$ & 27.3 & 12.20 & $34.0 \%$ & $60.0 \%$ \\
\hline & 7\# & 1.19 & 0.425 & 1.19 & $24.0 \%$ & 15.6 & 8.70 & $31.0 \%$ & $73.4 \%$ \\
\hline & 8\# & 1.36 & 0.650 & 1.44 & $32.0 \%$ & 23.5 & 10.60 & $29.0 \%$ & $69.4 \%$ \\
\hline & 9\# & 0.89 & 0.584 & 1.42 & $26.0 \%$ & 14.2 & 8.30 & $33.0 \%$ & $86.5 \%$ \\
\hline & $10 \#$ & 1.73 & 0.676 & 1.47 & $26.0 \%$ & 18.8 & 8.40 & $23.0 \%$ & $85.5 \%$ \\
\hline & Mean & 1.21 & 0.600 & 1.46 & $27.0 \%$ & 19.9 & 9.60 & $30.0 \%$ & $75.0 \%$ \\
\hline
\end{tabular}

Table 7. Variables of the of the built environment attributes of 5 neighborhoods in Hexi Area.

\begin{tabular}{|c|c|c|c|c|c|c|c|c|c|}
\hline \multirow{2}{*}{ Area } & \multirow{2}{*}{ Neighborhood } & \multirow{2}{*}{$\begin{array}{l}\text { Neighborhood } \\
\text { Area }\left(\mathrm{km}^{2}\right)\end{array}$} & \multicolumn{3}{|c|}{ Land Use Dimension } & \multicolumn{3}{|c|}{ Road Network System Dimension } & \multirow{2}{*}{$\begin{array}{c}\begin{array}{c}\text { Transit Facilities } \\
\text { Dimension }\end{array} \\
\text { Coverage of the } \\
\text { Transit Station (\%) }\end{array}$} \\
\hline & & & $\begin{array}{l}\text { Mixed Degree of } \\
\text { Land Use }\end{array}$ & $\begin{array}{l}\text { Floor Space } \\
\text { Ratio }\end{array}$ & $\begin{array}{c}\text { Building } \\
\text { Coverage (\%) }\end{array}$ & $\begin{array}{c}\text { Road Network } \\
\text { Connectivity (Scores) }\end{array}$ & $\begin{array}{c}\text { Road Network } \\
\text { Density }\left(\mathbf{k m} / \mathbf{k m}^{2}\right)\end{array}$ & $\begin{array}{l}\text { Road Area } \\
\text { Ratio (\%) }\end{array}$ & \\
\hline \multirow{6}{*}{ Hexi } & 11\# & 1.59 & 0.499 & 2.55 & $17.0 \%$ & 10.4 & 7.5 & $28.0 \%$ & $93.1 \%$ \\
\hline & $12 \#$ & 1.06 & 0.588 & 1.22 & $21.0 \%$ & 12.6 & 7.8 & $26.0 \%$ & $80.8 \%$ \\
\hline & $13 \#$ & 1.26 & 0.688 & 2.05 & $14.0 \%$ & 18.0 & 9.9 & $35.0 \%$ & $64.9 \%$ \\
\hline & $14 \#$ & 1.04 & 0.317 & 2.29 & $15.0 \%$ & 14.8 & 8.9 & $32.0 \%$ & $100.0 \%$ \\
\hline & $15 \#$ & 0.66 & 0.549 & 2.11 & $15.0 \%$ & 17.9 & 9.5 & $31.0 \%$ & $72.4 \%$ \\
\hline & Mean & 1.12 & 0.528 & 2.04 & $16.0 \%$ & 14.7 & 8.7 & $30.0 \%$ & $75.0 \%$ \\
\hline
\end{tabular}




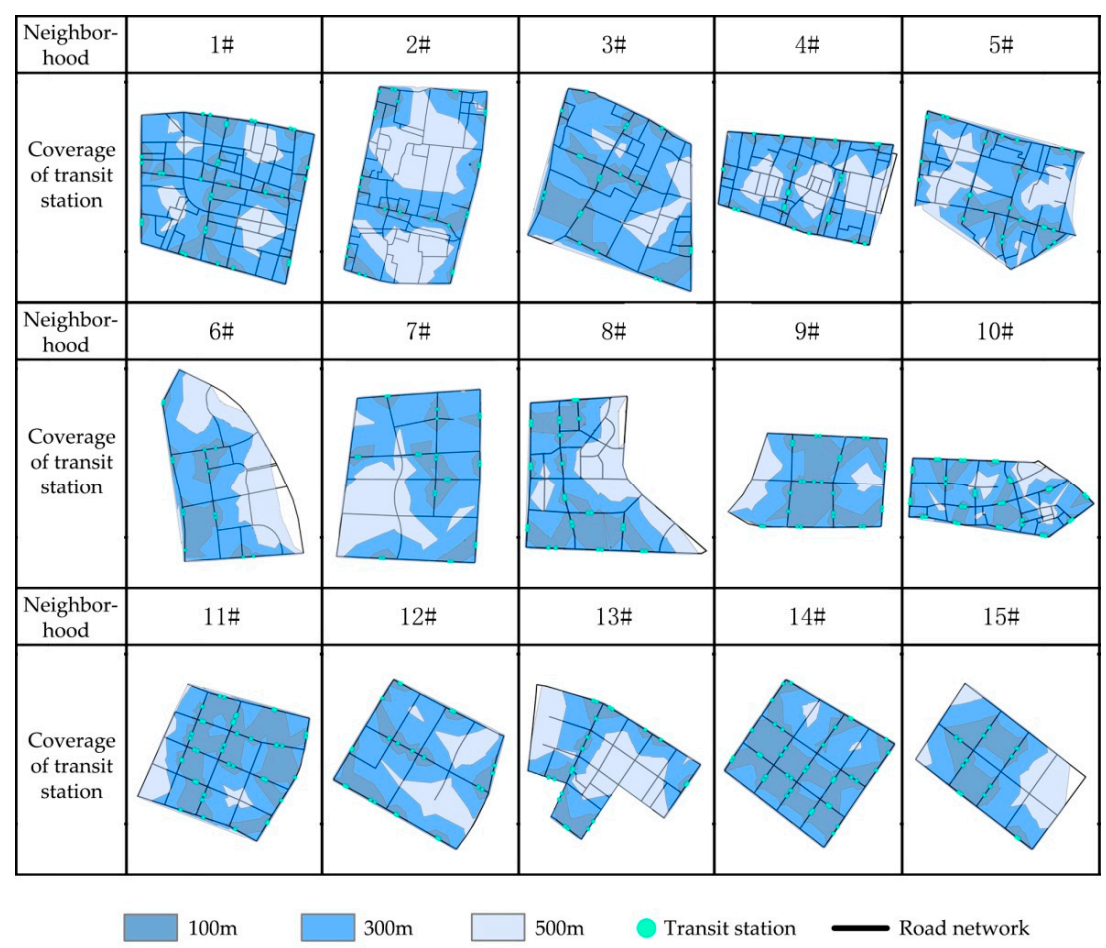

Figure 9. Coverage of transit station of 15neighborhoods.

From the 1970s to the 2000s, the neighborhood construction in Nanjing urban area showed a basic trend of more mixed land use and decreasing building densities. The road area ratio did not change much, but road connectivity and road network density gradually decreased and road width was increasing observably.

\section{The Correlation Analysis of Various Influencing Factors and Residents' Low-Carbon Travel}

Pearson correlation analysis in SPSS software is used to establish the bivariate correlation model which respectively combines the share of low-carbon travel of three purposes, the share of low-carbon travel overall with the residents' socio-economic attributes and the built environment attributes. The independent variables are divided into two categories. One is residents' socio-economic attributes and the other is the built environment of sample neighborhoods. The dependent variables are the share of residents' low-carbon travel modes for commuter travel, utilitarian travel, recreational travel and overall travel, respectively $\mathrm{P}_{\mathrm{CT}}, \mathrm{P}_{\mathrm{UT}}, \mathrm{P}_{\mathrm{RT}}, \mathrm{P}_{\mathrm{OT}}$.

\subsection{Variables of Residents' Socio-Economic Attributes}

The results of the analysis of the correlation between the share of low-carbon travel and the variables of residents' socio-economic attributes are shown in Table 8.

By comparison, it can be found that:

- Residents in the age group of 33 to 60 are less inclined to choose low-carbon travel, that is, middle-aged people may choose to use the car as travel mode.

- Residents with lower education level and lower income account for a higher share of low-carbon travel, which is mainly due to the relatively limited choices of travel mode.

- Family car ownership is a significant independent variable. No matter for the commuting travel, utilitarian travel or recreational travel, families with one car are more likely to travel by car. For commuting trips, families with more than two cars are more likely to choose cars as the travel mode, while for other purposes, the impact of this variable on the choice of travel modes is not clearly characterized. Families without cars undoubtedly become practitioners of low-carbon travel. 
Table 8. The bivariate correlation model for share of residents' low-carbon travel and residents' socio-economic attributes.

\begin{tabular}{|c|c|c|c|c|c|c|c|c|c|}
\hline \multirow{2}{*}{\multicolumn{2}{|c|}{ Residents' Socio-Economic Attributes }} & \multicolumn{2}{|c|}{ Commuter Travel } & \multicolumn{2}{|c|}{ Utilitarian Travel } & \multicolumn{2}{|c|}{ Recreational Travel } & \multicolumn{2}{|c|}{ Overall Travel } \\
\hline & & \multirow{3}{*}{$\begin{array}{c}\begin{array}{c}\text { Correlation } \\
\text { Coefficient }\end{array} \\
0.138 \\
-0.138\end{array}$} & \multirow{3}{*}{$\begin{array}{c}\text { Sig } \\
(-0.623) \\
(0.623)\end{array}$} & \multirow{3}{*}{$\begin{array}{c}\text { Correlation } \\
\text { Coefficient }\end{array}$} & \multirow{3}{*}{$\begin{array}{c}\text { Sig } \\
(0.849) \\
(0.849) \\
\end{array}$} & \multirow{3}{*}{$\begin{array}{c}\text { Correlation } \\
\text { Coefficient }\end{array}$} & \multirow{3}{*}{$\begin{array}{c}\text { Sig } \\
(0.849) \\
(0.849)\end{array}$} & \multirow{3}{*}{\begin{tabular}{|c|}
$\begin{array}{c}\text { Correlation } \\
\text { Coefficient }\end{array}$ \\
0.068 \\
-0.068 \\
\end{tabular}} & \multirow{3}{*}{$\begin{array}{c}\text { Sig } \\
(0.809) \\
(0.809) \\
\end{array}$} \\
\hline & male & & & & & & & & \\
\hline Sex ratio & female & & & & & & & & \\
\hline \multirow{4}{*}{ Age ratio } & 6 to 18 & 0.403 & $(0.136)$ & 0.228 & $(0.414)$ & 0.228 & $(0.414)$ & 0.330 & $(0.230)$ \\
\hline & 19 to 32 & 0.414 & $(0.125)$ & 0.447 & $(0.095)$ & 0.447 & $(0.095)$ & 0.402 & $(0.137)$ \\
\hline & 33 to 60 & -0.579 & $(0.024 *)$ & -0.673 & $\left(0.006^{* *}\right)$ & -0.673 & $\left(0.006^{* *}\right)$ & -0.630 & $(0.120)$ \\
\hline & over 60 & -0.041 & $(0.884)$ & 0.154 & $(0.583)$ & 0.154 & $(0.583)$ & 0.047 & $(0.869)$ \\
\hline \multirow{4}{*}{$\begin{array}{l}\text { Educational } \\
\text { attainment ratio }\end{array}$} & junior high school or below & 0.452 & $(0.091)$ & 0.583 & $\left(0.023^{*}\right)$ & 0.583 & $\left(0.023^{*}\right)$ & 0.653 & $\left(0.008^{* *}\right)$ \\
\hline & senior high school & -0.052 & $(0.854)$ & -0.081 & $(0.775)$ & -0.081 & $(0.775)$ & -0.145 & $(0.605)$ \\
\hline & junior college or college & 0.045 & $(0.874)$ & -0.143 & $(0.610)$ & -0.143 & $(0.610)$ & -0.149 & $(0.597)$ \\
\hline & master or above & -0.384 & $(0.158)$ & -0.263 & $(0.343)$ & -0.263 & $(0.343)$ & -0.301 & $(0.275)$ \\
\hline \multirow{3}{*}{$\begin{array}{l}\text { Family population } \\
\text { ratio }\end{array}$} & 1 & -0.509 & $(0.053)$ & -0.302 & $(0.274)$ & -0.302 & $(0.274)$ & -0.473 & $(0.075)$ \\
\hline & 2 to 3 & 0.349 & $(0.203)$ & -0.387 & $(0.154)$ & -0.387 & $(0.154)$ & -0.405 & $(0.135)$ \\
\hline & over 3 & -0.573 & $\left(0.026^{*}\right)$ & 0.347 & $(0.205)$ & 0.347 & $(0.205)$ & 0.512 & $(0.051)$ \\
\hline \multirow{4}{*}{$\begin{array}{l}\text { Annual household } \\
\text { income ratio }\end{array}$} & $¥ 50,000$ or below & 0.632 & $(0.012 *)$ & 0.427 & $(0.113)$ & 0.427 & $(0.113)$ & 0.675 & $\left(0.006^{* *}\right)$ \\
\hline & $¥ 50,000$ to $¥ 100,000$ & 0.302 & $(0.274)$ & 0.487 & $(0.066)$ & 0.487 & $(0.066)$ & 0.444 & $(0.097)$ \\
\hline & $¥ 100,000$ to $¥ 200,000$ & -0.204 & $(0.465)$ & -0.159 & $(0.570)$ & -0.159 & $(0.570)$ & -0.355 & $(0.194)$ \\
\hline & $¥ 200,000$ or above & -0.278 & $(0.316)$ & -0.315 & $(0.253)$ & -0.315 & $(0.253)$ & -0.252 & $(0.364)$ \\
\hline \multirow{3}{*}{ Car ownership ratio } & 0 & 0.852 & $(0.000 * *)$ & 0.685 & $\left(0.005^{* *}\right)$ & 0.685 & $\left(0.005^{* *}\right)$ & 0.840 & $(0.000 * *)$ \\
\hline & 1 & -0.540 & $\left(0.038^{*}\right)$ & -0.564 & $(0.029 *)$ & -0.564 & $(0.029 *)$ & -0.548 & $(0.034 *)$ \\
\hline & 2 or over & -0.560 & $(0.03 *)$ & -0.174 & $(0.535)$ & -0.174 & $(0.535)$ & -0.435 & $(0.105)$ \\
\hline
\end{tabular}




\subsection{Variables of Residential Built Environment}

The analysis of the correlation between the share of low-carbon travel and the built environment variables (as shown in Table 9) is carried out.

The analysis results of different travel purposes have some similarities and differences.

- In the dimension of land use, (1) the share of residents' low-carbon travel for commuting is significantly and positively correlated with the mixed degree of land use, floor space ratio and building coverage. (2) For residents' utilitarian travel, higher mixed degree of land use value and higher building coverage value could promote residents to choose low-carbon travel mode, while floor space ratio has no significant influence on residents' travel mode.

- In the dimension of road system, (1) road connectivity and road network density have a significant impact on residents' low-carbon travel, and the greater the two indexes are, the more they can promote residents' low-carbon travel. (2) The correlation between the road area ratio and residents' travel mode is not significant. The reason may be that the sample areas selected in this study have little difference in road area ratio, so it is difficult to determine whether the changes will affect the travel mode of residents.

- In the dimension of the transit service, the correlation between the coverage of transit station and residents' travel mode is insignificant for any purpose of travel, which is different from the preconception of the study and researchers' understanding. This result may be due to the fact that the average coverage of the three areas with the radius of $300 \mathrm{~m}$ reaches above $73 \%$. The number and distribution of transit station are appropriate and the differences between the areas are relatively small.

In addition, during the questionnaire survey, residents were found to do diverse recreational activities, and the distances to destinations for recreation vary from each other. Moreover, this study considered mainly the impact of origin place's built environment on travel mode, while destination place's built environment may play a part either. So in this study, the recreational travel mode did not show much significant correlation with variables. We will keep focusing on this problem for further research in a followed-up study.

Overall travel is a comprehensive manifestation of the three purposes of travel. For overall travel, there is no positive or negative change in coefficients of each variable of the results compared to three travel types, while the significance has a slight decrease. In addition, it is a more comprehensive and balanced result. According to Table 9, the variables of the built environment attributes in neighborhoods are selected, which have significant influence on residents' low-carbon travel overall:

- In the dimension of land use, there is a significant positive correlation between the two variables, mixed degree of land use and building coverage and residents' low-carbon travel, while the correlation between floor space ratio and residents' travel is insignificant.

- In terms of the dimension of road network system, road connectivity and road network density are significantly positively correlated with residents' low-carbon travel. 
Table 9. The bivariate correlation model for share of residents' low-carbon travel and built environment attributes.

\begin{tabular}{|c|c|c|c|c|c|c|c|c|c|}
\hline \multirow{2}{*}{\multicolumn{2}{|c|}{ Built Environment Attributes }} & \multicolumn{2}{|c|}{ Commuter Travel } & \multicolumn{2}{|c|}{ Utilitarian Travel } & \multicolumn{2}{|c|}{ Recreational Travel } & \multicolumn{2}{|c|}{ Overall Travel } \\
\hline & & \multirow{4}{*}{$\begin{array}{c}\begin{array}{c}\text { Correlation } \\
\text { Coefficient }\end{array} \\
0.739 \\
0.558 \\
0.563 \\
\end{array}$} & \multirow{4}{*}{$\begin{array}{c}\text { Sig } \\
\left(0.002^{* *}\right) \\
\left(0.031^{*}\right) \\
\left(0.029^{*}\right)\end{array}$} & \multirow{4}{*}{$\begin{array}{c}\begin{array}{c}\text { Correlation } \\
\text { Coefficient }\end{array} \\
0.537 \\
0.491 \\
0.645\end{array}$} & \multirow{4}{*}{$\begin{array}{c}\text { Sig } \\
\left(0.039^{*}\right) \\
(0.063) \\
\left(0.009^{* *}\right)\end{array}$} & \multirow{4}{*}{$\begin{array}{c}\begin{array}{c}\text { Correlation } \\
\text { Coefficient }\end{array} \\
0.373 \\
0.193 \\
0.328\end{array}$} & \multirow{4}{*}{$\begin{array}{c}\text { Sig } \\
(0.172) \\
(0.491) \\
(0.233)\end{array}$} & \multirow{4}{*}{$\begin{array}{c}\begin{array}{c}\text { Correlation } \\
\text { Coefficient }\end{array} \\
0.699 \\
0.443 \\
0.565 \\
\end{array}$} & \multirow{4}{*}{$\begin{array}{c}\text { Sig } \\
\left(0.004^{* *}\right) \\
(0.098) \\
\left(0.028^{*}\right)\end{array}$} \\
\hline & mixed degree of land use & & & & & & & & \\
\hline Land use & floor space ratio & & & & & & & & \\
\hline & building coverage & & & & & & & & \\
\hline \multirow{3}{*}{$\begin{array}{c}\text { Road network } \\
\text { system dimension }\end{array}$} & $\begin{array}{c}\text { road network } \\
\text { connectivity }\end{array}$ & 0.600 & $(0.018 *)$ & 0.571 & $\left(0.026^{*}\right)$ & 0.204 & $(0.467)$ & 0.588 & $(0.021 *)$ \\
\hline & road network density & 0.604 & $\left(0.017^{*}\right)$ & 0.560 & $(0.030 *)$ & 0.132 & $(0.639)$ & 0.566 & $(0.028 *)$ \\
\hline & road area ratio & 0.157 & $(0.577)$ & 0.160 & $(0.568)$ & 0.101 & $(0.720)$ & 0.059 & $(0.853)$ \\
\hline $\begin{array}{l}\text { Transit facilities } \\
\text { dimension }\end{array}$ & $\begin{array}{l}\text { coverage of the } \\
\text { transit station }\end{array}$ & -0.261 & $(0.347)$ & -0.095 & $(0.737)$ & -0.068 & $-(0.810)$ & -0.095 & $(0.737)$ \\
\hline
\end{tabular}




\section{The Key Significant Variables of the Built Environment}

Based on the 4866 travel trips in total (consisting of commuter travel, utilitarian travel and recreational travel), taking the odds ratio of the low-carbon travel mode and the motorized travel mode as the dependent variable, taking the built environment variables as the independent variables, with residents' socio-economic attributes as concomitant variables, the multivariate logit regression model is established. The regression results are as shown in Tables 10 and 11.

Table 10. The multivariate logit regression model for residents overall travel in land use dimension.

\begin{tabular}{ccccccc}
\hline & & Beta & Standard Error & Wald & Sig & Odds Ratio \\
\hline \multirow{2}{*}{$\begin{array}{c}\text { Land use } \\
\text { dimension }\end{array}$} & mixed degree of land use & 1.664 & 0.381 & 19.092 & $\left(0.000^{* *}\right)$ & 5.278 \\
\cline { 2 - 7 } & Floor space ratio & 0.150 & 0.148 & 1.022 & $(0.312)$ & 0.861 \\
\cline { 2 - 7 } building coverage & 1.583 & 0.957 & 2.737 & $(0.098)$ & 4.868 \\
\hline \multirow{2}{*}{$\begin{array}{c}\text { Socio-economic } \\
\text { attributes }\end{array}$} & $\begin{array}{c}\text { junior high school degree } \\
\text { or below }\end{array}$ & 0.515 & 0.196 & 6.937 & $\left(0.008^{* *}\right)$ & 1.674 \\
\cline { 2 - 7 } & \begin{tabular}{c} 
car ownership \\
\cline { 2 - 7 }
\end{tabular} & -0.868 & 0.074 & 135.794 & $\left(0.000^{* *}\right)$ & 0.420 \\
\hline annual household income & 0.220 & 0.205 & 1.159 & $(0.282)$ & 1.246 \\
\hline constant & 0.902 & 0.198 & 20.695 & $(0.000 * *)$ & 2.466 \\
\hline
\end{tabular}

Table 11. The multivariate logit regression model for residents overall travel in road network system dimension.

\begin{tabular}{ccccccc}
\hline & Beta & Standard Error & Wald & Sig & Odds Ratio \\
\hline \multirow{2}{*}{$\begin{array}{c}\text { Road network } \\
\text { system } \\
\text { dimension }\end{array}$} & $\begin{array}{c}\text { road network } \\
\text { connectivity }\end{array}$ & 0.004 & 0.001 & 9.704 & $(0.002 * *)$ & 1.004 \\
\cline { 2 - 7 } & road network density & 0.130 & 0.064 & 4.146 & $\left(0.042^{*}\right)$ & 1.139 \\
\hline $\begin{array}{c}\text { junior high school degree } \\
\text { or below }\end{array}$ & 0.408 & 0.174 & 5.531 & $\left(0.000^{* *}\right)$ & 1.504 \\
\cline { 2 - 7 } $\begin{array}{c}\text { Socio-economic } \\
\text { attributes }\end{array}$ & \begin{tabular}{c} 
car ownership \\
\cline { 2 - 7 }
\end{tabular} & -0.680 & 0.166 & 16.690 & $\left(0.000^{* *}\right)$ & 1.974 \\
\hline $\begin{array}{c}\text { annual household income } \\
50,000 \text { or below }\end{array}$ & 0.903 & 0.060 & 226.857 & $\left(0.000^{* *}\right)$ & 0.405 \\
\hline constant & 2.542 & 0.395 & 41.385 & $(0.001 * *)$ & 12.711 \\
\hline
\end{tabular}

In the dimension of land use, except for the mixed degree of land use, the other variables are not significantly related to the modes of residents' travel. This indicates that in combination with the variables of socio-economic attributes that significantly affect residents' travel, among the land use variables, the mixed degree of land has the highest impact on the travel mode of residents. The higher the mixed degree of land is, the more it can promote the low-carbon travel of residents.

In the dimension of road network system, the analysis result shows that combined with residents' socio-economic attributes, road network connectivity and road network density have significant correlation with residents' travel mode, both of which have a greater impact on residents' travel modes and the correlation is positive.

\section{Estimation of the Recommended Value of the Key Significant Variables of Built Environment}

Sections above have screened out the key variables of the built environment affecting the modes of residents' travel: the mixed degree of land use, road network connectivity and road network density. The following scatter plots of the share of low-carbon travel overall and the key variables of the built 
environment of neighborhoods, as well as the linear regression model are used to explore in depth the relationship between the key significant attributes of built environment and residents' low-carbon travel. Figures 10-12 respectively show the scatter plot of the mixed degree of land use, road network connectivity, road network density and residents' share of low-carbon travel. According to the trend line drawn by scattered points, there may be some linear relationship between the three variables of the built environment and the share of residents' low-carbon travel. Therefore, linear regression equations are established to determine whether the regression results are significant.

\subsection{Land Use Dimension: Mixed Degree of Land Use}

The regression results of the share of the low-carbon travel for different purposes and the mixed degree of land use are shown in Table 12. Combined with Figure 10, with the confidence level of 95\%, the increase in the mixed degree of residential land could significantly promote residents to choose low-carbon travel for commuting travel, utilitarian travel and overall travel.

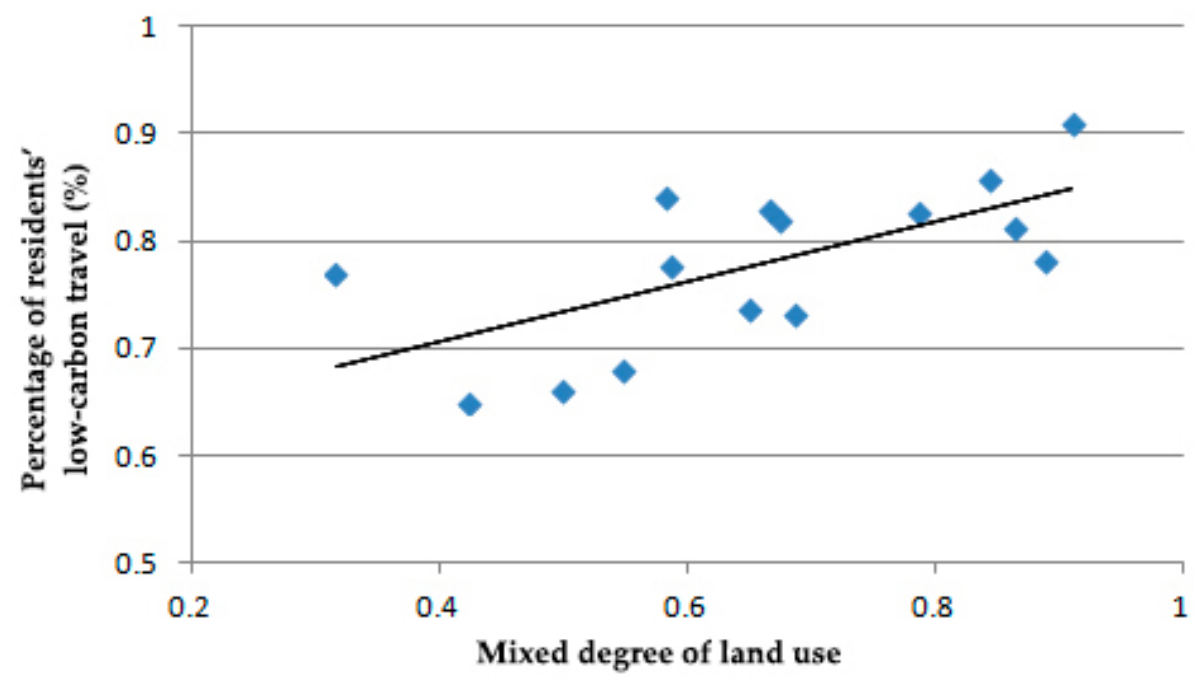

Figure 10. Relationship between residents' low-carbon travel overall and mixed degree of land use.

Table 12. The liner regression model for residents' low-carbon travel and mixed degree of land use.

\begin{tabular}{ccccc}
\hline Travel Type & $\mathbf{R}^{2}$ & Coefficient & Constant & Sig. \\
\hline overall travel & 0.425 & 0.281 & 0.593 & $\left(0.04^{* *}\right)$ \\
commuter travel & 0.599 & 0.478 & 0.739 & $\left(0.02^{* *}\right)$ \\
utilitarian travel & 0.202 & 0.183 & 0.537 & $\left(0.039^{*}\right)$ \\
recreational travel & 0.139 & 0.178 & 0.373 & $(0.172)$ \\
\hline
\end{tabular}

It can be considered that, with the other variables unchanged, a 0.1 increase in the mixed degree of land use may lead to the increase of $2.81 \%$ in the share of low-carbon travel overall, of $4.78 \%$ in commuting travel, and of $1.83 \%$ in utilitarian travel. However, in this study, the mixed degree of land use has no significant influence on the modes choice for residents' recreational travel.

Assuming other influential variables remain unchanged, the linear regression equation for the share of low-carbon travel in the overall travel $\mathrm{P}_{\mathrm{OT}}$ and mixed degree of land use $\mathrm{X}_{\text {mix }}$ is: $\mathrm{P}_{\mathrm{OT}}=0.281 \mathrm{X}_{\text {mix }}+0.593$.

The equation implies that, with other influential variables unchanged, the increase of 0.1 in the mixed degree of land use will lead to the growth of $2.81 \%$ of the share of residents' low-carbon travel in neighborhood. 
In this study, $80 \%$ of the low-carbon travel is regarded as a measure of low-carbon travel-oriented neighborhoods, and selection of the measure $80 \%$ is due to two reasons. First, it is with reference to the share of low-carbon travel in Hong Kong. Hong Kong has a dense population and a compact urban form. It is one of the representative cities for sustainable development in the world. According to the statistics of Hong Kong's Transport Department, Hong Kong's daily travel share of low-carbon transport is as high as $90 \%$ [32]. Second, the survey results of this empirical study show that the average share of low-carbon neighborhoods in Xinjiekou Area exceeds 80\%, reaching a relatively high level, which is related to its traditional urban texture and relatively short of parking spaces. However, there is still a big gap between the share of low-carbon travel in other areas and Xinjiekou Area. Compared with Hong Kong, the gap is even greater. Based on the specific conditions of Nanjing city, this paper selects $80 \%$ of the low-carbon travel as the current measurement.

Put $\mathrm{P}_{\mathrm{OT}}=80 \%$ into the equation and obtain the corresponding mixed degree of land use of 0.736 , so it is recommended that the mixed degree of land use for low-carbon travel-oriented neighborhoods should be above 0.736 .

\subsection{Road Network System Dimension}

(1) Road network connectivity

The results of the linear regression of residents' low-carbon travel and road network connectivity under different travel purposes are shown in Table 13. Combined with Figure 11, under the $95 \%$ confidence level, the improved road network connectivity has significant impact on residents' choice of the low-carbon travel mode for commuting travel, utilitarian travel and overall travel, with a relatively higher influence on the overall travel.

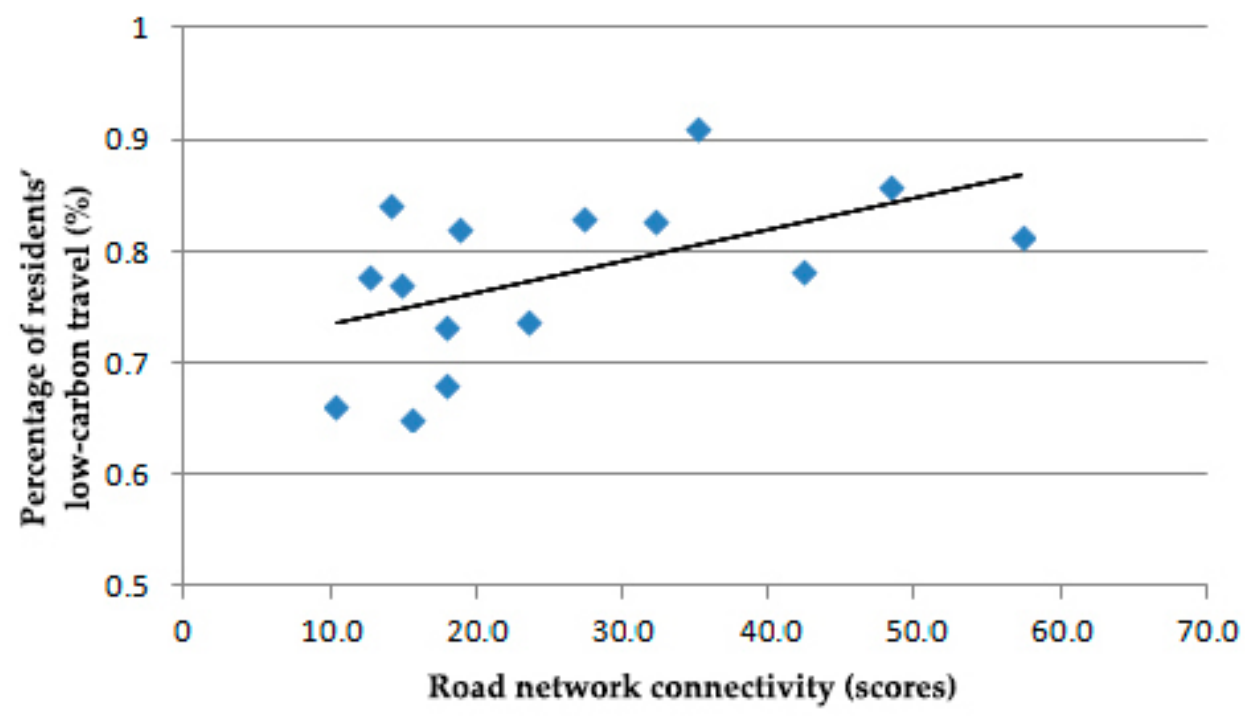

Figure 11. Relationship between residents' low-carbon travel overall and road network connectivity.

Table 13. The liner regression model for residents' low-carbon travel and road network connectivity.

\begin{tabular}{ccccc}
\hline Travel Type & $\mathbf{R}^{2}$ & Coefficient & Constant & Sig. \\
\hline overall travel & 0.345 & 0.003 & 0.699 & $\left(0.021^{*}\right)$ \\
commuter travel & 0.361 & 0.002 & 0.601 & $\left(0.018^{*}\right)$ \\
utilitarian travel & 0.256 & 0.002 & 0.506 & $\left(0.044^{*}\right)$ \\
recreational travel & 0.184 & 0.002 & 0.289 & $(0.296)$ \\
\hline \multicolumn{5}{c}{ Significance $(* 5 \%)}$.
\end{tabular}

Significance $\left.{ }^{*}=5 \%\right)$. 
For every 1-point increase in the road network connectivity while maintaining the other variables of impact, the share of low-carbon travel overall increases by $0.3 \%$, while the share of low-carbon travel in commuting and utilitarian increases by $0.2 \%$. In this research, the road network connectivity also has no significant impact on the recreational travel.

It is still assumed that the other influencing factors remain unchanged, and the linear regression equation for determining the share of residents' low-carbon travel overall $\mathrm{P}_{\mathrm{OT}}$ and the connectivity of residential roads $X_{\mathrm{rc}}$ is as follows: $\mathrm{P}_{\mathrm{OT}}=0.003 \mathrm{X}_{\mathrm{rc}}+0.699$.

The equation implies that for every 1-point increase in the road network connectivity, the share of low-carbon travel of residents living in neighborhoods will increase by $0.3 \%$ when other influential variables remain unchanged. Taking $80 \%$ of low-carbon travel as the measure of low-carbon travel oriented neighborhood, substitute $\mathrm{P}_{\mathrm{OT}}=80 \%$ into the equation and obtain the corresponding road connectivity value of 33.7 points. Therefore, it is recommended that the road network connectivity of low-carbon travel-oriented neighborhood is more than 33.7 points.

\section{(2) Road network density}

The linear regression results of the share of low-carbon travel in neighborhoods and the residential road network density under different travel purposes are shown in Table 14, combined with the scatter Figure 12.

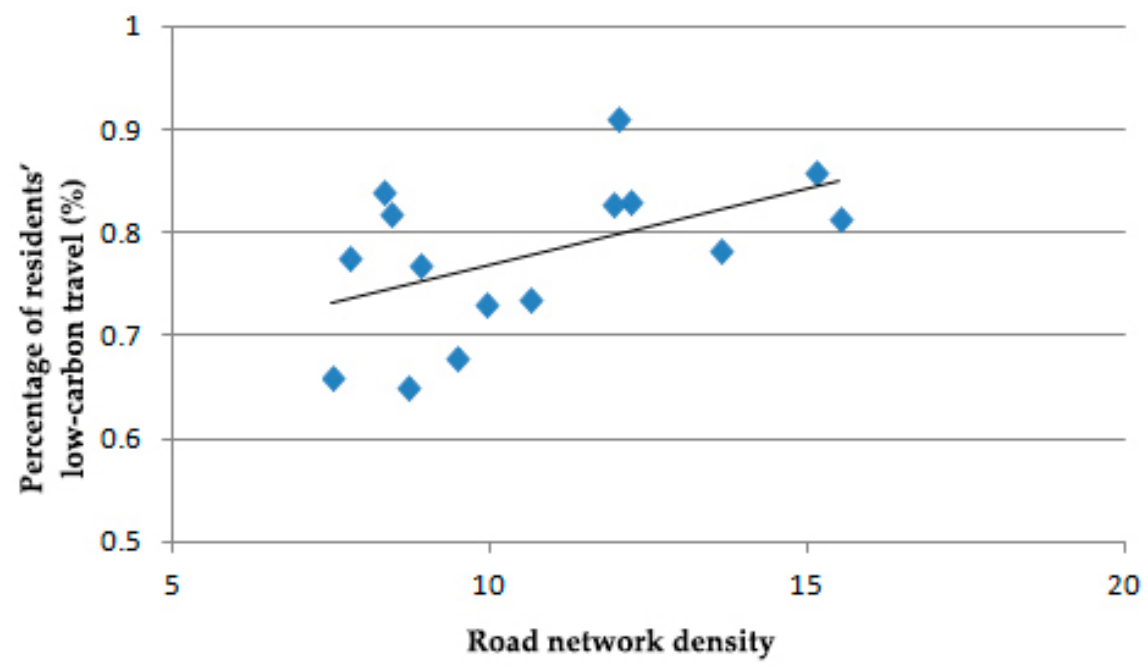

Figure 12. Relationship between residents' low-carbon travel overall and road network density.

Table 14. The liner regression model for residents' low-carbon travel and road network density.

\begin{tabular}{ccccc}
\hline Travel Type & $\mathbf{R}^{2}$ & Coefficient & Constant & Sig. \\
\hline overall travel & 0.321 & 0.016 & 0.607 & $\left(0.028^{*}\right)$ \\
commuter travel & 0.357 & 0.028 & 0.598 & $\left(0.019^{*}\right)$ \\
utilitarian travel & 0.251 & 0.012 & 0.501 & $(0.057)$ \\
recreational travel & 0.158 & 0.008 & 0.241 & 0.387 \\
\hline
\end{tabular}

Significance $\left({ }^{*}=5 \%\right)$.

It can be considered that under the $95 \%$ confidence level, the increased residential road network density has significant impact on residents' low-carbon travel overall and the choice of low-carbon travel modes on commute travel, with relatively higher influence on commute travel: for a $1 \mathrm{~km} / \mathrm{km}^{2}$ increases in the residents' road network density while the other influential variables remain unchanged, we see a $1.6 \%$ increase in the share of low-carbon travel overall, $2.8 \%$ increase in that of commuting 
travel, and $1.2 \%$ increase in that of utilitarian travel. The residential road network density also shows no significant influence on recreational travel.

Still assuming other factors remain unchanged, the linear regression equation for determining the share of low-carbon travel of residents $P_{\mathrm{OT}}$ and the residential road network density $\mathrm{X}_{\mathrm{rd}}$ is: $\mathrm{P}_{\mathrm{OT}}=0.016 \mathrm{X}_{\mathrm{rd}}+0.607$.

The equation implies that under the overall travel, for every increase in residential road network density of $1 \mathrm{~km} / \mathrm{km}^{2}$, the share of residents' low-carbon travel increases by $1.6 \%$. Taking $80 \%$ of low-carbon travel as the measure of low-carbon travel-oriented neighborhood, substitute $\mathrm{P}_{\mathrm{OT}}=80 \%$ into the equation to obtain the corresponding road network density value of $12.1 \mathrm{~km} / \mathrm{km}^{2}$. Therefore, it is recommended that the road network density of low-carbon travel-oriented c neighborhood is above $12.1 \mathrm{~km} / \mathrm{km}^{2}$.

Based on the analysis above, it can be considered as follows:

- For different travel purposes for residents, the built environment variables have different impacts on the share of low-carbon travel in neighborhoods, and the optimization of built environment variables should be based on the types of travels. It is necessary to clear out the characteristic of the target neighborhood, and then put forward targeted design guide or suggestions for improvement.

- This study focuses on the impact of the built environment of origin-neighborhood on travel. As destinations and trip distances of the surveyed residents' recreational travel vary from each other, the research on the influential factors of residents' recreational travel mode can be further incorporated into the contents of the destination environment and travel distance.

- In order to build low-carbon travel oriented neighborhood, it is recommended that in the dimension of land use, the mixed degree of residential land use should be higher than 0.736 . In the dimension of road network system, the recommended value of road network connectivity is above 33.7 points, and the density of road network is recommended to be above $12.1 \mathrm{~km} / \mathrm{km}^{2}$.

\section{Conclusions}

With the growth in automobile inventory and use yearly, environment pollution, energy consumption and urban transport problems have brought severe challenge for social development. Many researchers have conducted studies of urban planning and traffic design, aimed at reducing the emission of $\mathrm{CO}_{2}$ and alleviating the traffic jam. With the purpose of proposing suggestions for the construction of low-carbon travel neighborhood, this study takes Nanjing as the study area. From the neighborhood level, it provides additional insights into the linkages between built environment and residents' travel mode. Based on the survey and data collection of residents' travel, residents' socio-economic attributes and built environment attributes, a correlation analysis model, a multivariate logit regression model and an unary linear regression model are successively applied. For the consideration that potential variables are numerous and vary from different aspects, it is necessary to apply more than one kind of model and to twice screen out the key significant variables.

The results show that residents' socio-economic attributes and residential built environment attributes both have influences on residents' travel mode. In addition, the influence of each variable on residents' travel may vary from different purposes of travel. Specifically, from the aspect of residents' socio-economic attributes, age, educational attainment, annual household income and car ownership are significant for influence on residents' travel mode. Built environment attributes are classified into three dimensions of land use, road network system and transit service. An increase in the share of low-carbon travel is positive correlation with variables of mixed degree of land use, floor area ratio, building coverage, road network connectivity and road network density. For urban planning, neighborhood construction is supposed to be denser, more mixed land use, higher road network density and road network connectivity. Moreover, among the residential built environment attributes, mixed degree of land use, road network density and road network connectivity are key significant attributes, which influence residents' travel mode most. Accordingly, relevant planning and policy formulation call for more concentration on these three variables. Furthermore, based on the significant linear relationship between residents' travel mode and this 3 variables, recommended values of these 
3 variables are proposed for the construction of low-carbon travel oriented neighborhood: the mixed degree of land use recommended to be over 0.736 , road network connectivity recommended to be over 33.7 and road network density recommended to be over $12.1 \mathrm{~km} / \mathrm{km}^{2}$.

This study is an empirical study of the urban area of Nanjing, indicating the significant correlation between built environment variables and residents' travel mode. The results of this study are referential especially for neighborhoods which are with high population density, with relatively large-scale blocks and gated or semi-gated type in developing countries. However, it needs to be clarified that the research in this paper may produce different research conclusions compared with other regions, and still needs to be combined with the local situation to put forward suggestions for the optimization of the specific built environment. In addition, the factors influencing residents' travel mode are numerous and complex. There are still some aspects that have not been considered in this study. The other factors that affect the modes of residents' travel need to be further studied.

Acknowledgments: This study was supported by National Natural Science Foundation of China (No. 51508265 and No. 51578282); Natural Science Research Project of Colleges and Universities in Jiangsu Province (No. 15KJB560006); Natural Science Foundation of Jiangsu Province, China (No. BK20151538); Science and Technology Project of Ministry of Housing and Urban-Rural Development of China (2016-K2-027); and Foundation of the "333 High-Level Talents" of Jiangsu Province (No. BRA2016417)

Author Contributions: Caiyun Qian designed the analytical framework and revised the paper. Yang Zhou designed the analytical framework, co-wrote and revised the paper. Ze Ji constructed the model, analyzed the data and co-wrote the paper. Qing Feng assisted the collection of research data. All authors read and approved the final manuscript.

Conflicts of Interest: The authors declare no conflict of interest.

\section{References}

1. Intergovernmental Panel on Climate Change. Climate Change 2014: Synthesis Report. Contribution of Working Groups I, II and III to the Fifth Assessment Report of the Intergovernmental Panel on Climate Change; Core Writing Team, Pachauri, R.K., Meyer, L.A., Eds.; IPCC: Geneva, Switzerland, 2014; 151p.

2. National Bureau of Statistics of China. China Statistical Yearbook 2016; China Statistics Press: Beijing, China, 2016.

3. Cao, X.; Mokhtarian, P.L.; Handy, S.L. The relationship between the built environment and non-work travel: A case study of Northern California. Transp. Res. Part A 2009, 43, 548-559.

4. Rodríguez, D.A.; Joo, J. The relationship between non-motorized mode choice and the local physical environment. Transp. Res. Part D Transp. Environ. 2004, 9, 151-173. [CrossRef]

5. Agrawal, A.W.; Schimek, P. Extent and correlates of walking in the USA. Transp. Res. Part D Transp. Environ. 2007, 12, 548-563. [CrossRef]

6. Okada, A. Is an increased elderly population related to decreased $\mathrm{CO}_{2}$ emissions from road transportation. Energy Policy 2012, 45, 286-292. [CrossRef]

7. Wei, Y.P.; Pan, C.L. Urban land-use characteristics and commuters' travel pattern: A case study of west Hangzhou. City Plan. Rev. 2012, 36, 76-84.

8. Huang, J.N.; Du, N.R.; Liu, P.; Han, S.S. An Exploration of Land Use Mix Around Residence and Family Commuting Caused Carbon Emission: A Case Study of Wuhan City in China. Urban Plan. Int. 2013, 28, 25-30.

9. Huang, J.N.; Gao, H.W.; Han, S.S. The Effect of Traffic Facilities Accessibility on Household Commuting Caused Carbon Emission: A Case Study of Wuhan City, China. Urban Plan. Int. 2015, 30, 97-105.

10. Merlin, L.A. Can the built environment influence nonwork activity participation? An analysis with national data. Transportation 2015, 42, 369-387. [CrossRef]

11. Cervero, R.; Kockelman, K. Travel demand and the 3Ds: Density, diversity, and design. Transp. Res. Part D Transp. Environ. 1997, 2, 199-219. [CrossRef]

12. Cervero, R.; Jin, M. Rail + Property Development: A Model of Sustainable Transit Finance and Urbanism; Research Report; Institute of Urban and Regional Development, University of California at Berkeley: Berkeley, CA, USA, 2008.

13. Greenwald, M.; Boarnet, M. Built Environment as Determinant of Walking Behavior: Analyzing Non-work Pedestrian Travel in Portland, Oregon. Transp. Res. Record J. Transp. Res. Board 2001, 1780, 33-41. [CrossRef] 
14. Hensher, D.A. TRESIS: A transportation, land use and environmental strategy impact simulator for urban areas. Transportation 2002, 29, 439-457. [CrossRef]

15. Kitamura, R.; Mokhtarian, P.L.; Laidet, L. A micro-analysis of land use and travel in five neighborhoods in the San Francisco Bay Area. Transportation 1997, 24, 125-158. [CrossRef]

16. Reilly, M.; Landis, J. The Influence of Built-Form and Land Use on Mode Choice Evidence from the 1996 Bay Area Travel Survey. Presented at the 81st Annual Meeting of the Transportation Research Board, Washington, DC, USA, 13-17 January 2002.

17. Dygryn, J.; Mitas, J.; Stelzer, J. The Influence of Built Environment on Walkability Using Geographic Information System. J. Hum. Kinet. 2010, 24, 179-198. [CrossRef]

18. Ewing, R.; Cervero, R. Travel and the Built Environment. J. Am Plan Assoc. 2010, 76, 265-294. [CrossRef]

19. Hong, J.; Shen, Q.; Zhang, L. How do built-environment factors affect travel behavior? A spatial analysis at different geographic scales. Transportation 2014, 41, 419-440. [CrossRef]

20. Ding, C.; Wang, Y.; Xie, B.; Liu, C. Understanding the Role of Built Environment in Reducing Vehicle Miles Traveled Accounting for Spatial Heterogeneity. Sustainability 2014, 6, 589-601. [CrossRef]

21. Pan, H.X.; Shen, Q.; Zhang, M. Impacts of Urban Forms on Travel Behavior: Case Studies in Shanghai. Urban Transp. China 2009, 7, 28-32.

22. Shi, F.; Ju, Y. Analysis on influence factors of public transportation share: An empirical study of central Nanjing. City Plan. Rev. 2015, 39, 76-84.

23. Chen, Y.; Wang, Q.Y.; Xi, W.Q.; Mao, J. Influence of Spatial Form on Pedestrians. Planners 2017, 33, 74-80.

24. State Bureau of Technical Supervision, Ministry of Construction. Code for Transport Planning on Urban Road GB50220-95; China Architecture \& Building Press: Beijing, China, 1995.

25. Cochran, W. Sampling Techniques; John Wiley \& Sons: Boston, MA, USA, 1977.

26. Handy, S.; Cao, X.; Mokhtarian, P. Correlation or causality between the built environment and travel behavior? Evidence from Northern California. Transp. Res. Part D Transp. Environ. 2005, 10, 427-444. [CrossRef]

27. Bureau of Statistics of Nanjing. Statistical Yearbook of Nanjing 2016; China Statistics Press: Beijing, China, 2016.

28. Mercado, R.; Paez, A. Determinants of distance traveled with a focus on the elderly: A multilevel analysis in the Hamilton CMA, Canada. J. Transp. Geogr. 2009, 17, 65-76. [CrossRef]

29. Dang, Y.X.; Dong, G.P.; Yu, J.H.; Zhang, W.Z.; Shen, L. Impact of land-use mixed degree on resident's home-work separation in Beijing. Acta Geogr. Sin. 2015, 70, 919-930.

30. Dill, J. Measuring network connectivity for bicycling and walking. In Proceedings of the Transportation Research Board, Washington, DC, USA, 22-26 January 2012.

31. Nanjing Urban Planning Bureau. Nanjing Transport Annual Report 2015; Nanjing Institute of City \& Transport Planning Co. Ltd.: Nanjing, China, 2015.

32. Transport Department. Annual Traffic Census; Transport Department: Hong Kong, China, 2006. 